\title{
Land Cover and Crop Classification Based on Red Edge Indices Features of GF-6 WFV Time Series Data
}

\author{
Yupeng Kang ${ }^{1,2}$, Xinli Hu ${ }^{2, *}$, Qingyan Meng ${ }^{2,3,4}$, Youfeng Zou ${ }^{1}$, Linlin Zhang ${ }^{2,3,4} \mathbb{D}$, Miao Liu $^{2}$ \\ and Maofan Zhao ${ }^{2,3}$ \\ 1 School of Surveying and Land Information Engineering, Henan Polytechnic University, \\ Jiaozuo 454003, China; kangyphpu_x86@home.hpu.edu.cn (Y.K.); zouyf@hpu.edu.cn (Y.Z.) \\ 2 Aerospace Information Research Institute, Chinese Academy of Sciences, Beijing 100101, China; \\ mengqy@radi.ac.cn (Q.M.); zhangll@radi.ac.cn (L.Z.); liumiao@aircas.ac.cn (M.L.); \\ zhaomaofan19@mails.ucas.ac.cn (M.Z.) \\ 3 University of Chinese Academy of Sciences, Beijing 100049, China \\ 4 Hainan Research Institute, Aerospace Information Research Institute, Chinese Academy of Sciences, \\ Sanya 572029, China \\ * Correspondence: huxl@aircas.ac.cn; Tel.: +86-010-6485-2195
}

check for updates

Citation: Kang, Y.; Hu, X.; Meng, Q.; Zou, Y.; Zhang, L.; Liu, M.; Zhao, M. Land Cover and Crop Classification Based on Red Edge Indices Features of GF-6 WFV Time Series Data. Remote Sens. 2021, 13, 4522. https:// doi.org/10.3390/rs13224522

Academic Editors: Ignacio

A. Ciampitti, Liheng Zhong and Ran Meng

Received: 11 October 2021

Accepted: 5 November 2021

Published: 10 November 2021

Publisher's Note: MDPI stays neutral with regard to jurisdictional claims in published maps and institutional affiliations.

Copyright: (c) 2021 by the authors. Licensee MDPI, Basel, Switzerland. This article is an open access article distributed under the terms and conditions of the Creative Commons Attribution (CC BY) license (https:/ / creativecommons.org/licenses/by/ $4.0 /)$.

\begin{abstract}
Time series of vegetation indices can be utilized to capture crop phenology information, and have been widely used in land cover and crop classification, phenological feature extraction, and planting structure monitoring. This is of great significance for guiding agricultural production and formulating agricultural policies. According to the characteristics of the GF-6 satellite's newly-added red edge bands, wide field view and high-frequency imaging, the time series of vegetation indices about multi-temporal GF-6 WFV data are used for the study of land cover and crop classification. In this study, eight time steps of GF-6 WFV data were selected from March to October 2019 in Hengshui City. The normalized difference vegetation index (NDVI) time series and 10 different red edge spectral indices time series were constructed. Then, based on principal component analysis (PCA), using two feature selection and evaluation methods, stepwise discriminant analysis (SDA) and random forest (RF), the red edge vegetation index of normalized difference red edge (NDRE) was selected. Seven different lengths of NDVI, NDRE and NDVI\&NDRE time series were reconstructed by the Savizky-Golay (S-G) smoothing algorithm. Finally, an RF classification algorithm was used to analyze the influence of time series length and red edge indices features on land cover and crop classification, and the planting structure and distribution of crops in the study area were obtained. The results show that: (1) Compared with the NDRE red edge time series, the NDVI time series is more conducive to the improvement of the overall classification accuracy of crops, and NDRE can assist NDVI in improving the crop classification accuracy; (2) With the shortening of NDVI and NDRE time series, the accuracy of crop classification is gradually decreased, and the decline is gradually accelerated; and (3) Through the combination of the NDVI and NDRE time series, the accuracy of crop classification with different time series lengths can be improved compared with the single NDVI time series, which is conducive to improving the classification accuracy and timeliness of crops. This study has fully tapped the application potential of the new red edge bands of GF- 6 WFV time series data, which can provide references for crop identification and classification of time series data such as NDVI and red edge vegetation index of different lengths. At the same time, it promotes the application of optical satellite data with red edge bands in the field of agricultural remote sensing.
\end{abstract}

Keywords: GF-6 WFV data; time series; red edge indices; feature selection; crop classification

\section{Introduction}

Land cover and crop classification have become vital aspects of remote sensing satellite data applications [1]. Crop identification and classification by remote sensing is the basis for 
crop planting areas, growth monitoring, and crop yield estimation, which is an important part of agricultural remote sensing monitoring [2]. Due to the complexity and diversity of crop types and the small spectral differences among different crops, crop classification using a single time-phase remote sensing image is prone to producing the phenomena of "same object with different spectra" and "different objects with same spectrum", resulting in misclassification and mixed classification, and the classification accuracy is difficult to improve [3,4]. Time series remote sensing data can reflect the differences in the growth status of different crops, show different phenological characteristics, improve the separability and classification accuracy, and have been widely used in the field of agricultural remote sensing $[5,6]$.

The use of multi-temporal remote sensing data to a construct normalized difference vegetation index (NDVI) and other vegetation indices time series, combined with the seasonal rhythms and phenological differences of different crops, has been widely carried out in crop classification, which has improved the accuracy of crop classification. Wardlow et al. [7] used MODIS NDVI time series data to classify crops in Kansas, USA, and produced land use and land cover classification maps related to crops by using a hierarchical classification method. Hao et al. [8] used Landsat-5 TM and HJ-1 CCD data to obtain NDVI time series data with high temporal resolution through data combination, combined with the method of optimal classification phase selection and support vector machine classification to classify crops in the Bole and Manas counties of Xinjiang, China. Zhan et al. [9] constructed four kinds of time series with different time resolutions using MODIS EVI time series data, and used five different classifiers to classify crops in Kansas, USA. The study confirmed that the time series with high time resolution combined with random forest classifier had the highest classification accuracy. Belgiu et al. [10] adopted the time-weighted dynamic time warping (TWDTW) method to conduct pixel-based and object-oriented crop classification based on Sentinel-2 time series data in three different climatic regions of Romania, Italy, and California; compared with the random forest classification method, similar or better classification results were obtained, and TWDTW method was less sensitive in relation to the training samples. Based on the HJ-1 CCD satellite NDVI time series data, Liu et al. [11] used the decision classification technology based on NDVI threshold to estimate the classification and planting area of different crops in Hengshui City, Hebei Province, China. Zhang et al. [12] used multi-temporal landsat-8 OLI data to discuss the establishment method of crop classification knowledge rules based on NDVI time series, and carried out crop classification by remote sensing and planting area estimation in Quzhou County, Hebei Province, China. Huang et al. [13] selected four different vegetation indices features based on multi-temporal GF-1 WFV images, optimized the best period of classification and the combination of vegetation indices features, and used a random forest classification algorithm to extract the planting area of maize and soybean in Nenjiang County, Heilongjiang Province, China. Lebrini Y et al. [14] used four phenological metrics derived from twenty years of NDVI MODIS datasets (i.e., 2000-2019) to map and monitor changes in selected farming systems over a large arid-to-semi-arid region in Morocco. The above-mentioned studies have confirmed that the use of NDVI and other time series indices of multi-source remote sensing data can improve the classification accuracy of crops, and is suitable for crop identification and classification.

Although some advances have been made in crop classification using vegetation indices time series, it is mainly based on medium-low spatial resolution remote sensing images combined with some traditional vegetation indices time series such as NDVI and EVI at present [15-17]. For the moderate-to-high spatial resolution remote sensing images, especially the RapidEye, Sentinel-2, and GF-6 WFV remote sensing images with red edge or other vegetation sensitive bands, there are relatively few studies on the application of related red edge index to multi-temporal or time series crop classification. For example, Gerstmann et al. [18] used multi-temporal RapidEye data to design a variety of conventional vegetation indices and red edge vegetation indices, analyzed the phenological differences and separability of corn, rape, and winter wheat etc., and considered that the red edge index 
was helpful for crop identification and phenological monitoring. Wu et al. [19] used multitemporal Sentinel-2A data to construct a time series of NDVI and red edge normalized vegetation index (RENDVI), designed a variety of different combination features, and adopted the random forest algorithm to realize the fine classification of crops in Jingtai County, China. The classification results confirmed that RENDVI can assist NDVI to improve classification accuracy. Xiao et al. [20] established a red edge spectral index (RESI) method based on Sentinel-2 time series data from 2016 to 2018 to realize remote sensing identification and mapping of rubber plantations in Louang Namtha Province, northern Laos, and confirmed that the RESI method combined with phenology is helpful for improving the accuracy of rubber plantations' identification and classification.

Although red edge features have been applied to crop classification of multi-temporal or time series remote sensing data, the selection and evaluation of different red edge indices features are not sufficient, especially for Sentinel-2 and GF-6 WFV data with multiple red edge bands. In this study, according to the characteristics of GF-6 WFV data with two red edge bands, taking Hengshui City as the study area, land cover and crop classification was studied by using GF-6 WFV time series data in 2019. The objectives of this study are as follows: (1) using multi-temporal GF-6 WFV data to construct a variety of different red edge indices time series, select the red edge index time series with the highest classification importance, and design three different vegetation indices time series classification schemes combined with NDVI time series; and (2) random forest (RF) classification algorithm is used to analyze the influence of different time series length and optimal red edge index feature on the classification accuracy, which provides a reference for GF-6 WFV data to be better used in land cover and crop classification.

\section{Study Area and Data Sources}

\subsection{Overview of the Study Area}

Hengshui City is located in the southeast of Hebei Province, China, between $115^{\circ} 10^{\prime} \mathrm{E} \sim$ $116^{\circ} 34^{\prime} \mathrm{E}$ and $37^{\circ} 03^{\prime} \mathrm{N} \sim 38^{\circ} 23^{\prime} \mathrm{N}$. Hengshui City is selected as the study area and has jurisdiction over nine counties and districts, including Anping, Wuqiang, Wuyi, Jizhou, Zaoqiang, Gucheng, Raoyang, Shenzhou, etc., with a total area of about $8815 \mathrm{~km}^{2}$. Hengshui City is located in the Heilonggang Basin of the Huanghuaihai Plain, the grain production base in northern China. It belongs to the temperate continental monsoon climate zone. The climate is characterized by four distinct seasons, with large differences between cold and warm, and dry and wet. Hengshui City is a plain agricultural area with a large proportion of agricultural production in the economic structure. Natural vegetation in the territory is sparse, low in coverage, and simple in community structure. Crops are the most important type of vegetation. The main crops include winter wheat, summer maize, cotton, spring maize, peanuts, soybeans, fruit trees, etc., among which winter wheat-summer corn rotation is the most widely planted [11,21]. In recent years, due to the influence of the national fallow policy on the Heilonggang river basin, the agricultural planting structure has changed, which is suitable for remote sensing identification and classification of crops [22,23]. Combined with the local phenological calendar, field surveys were conducted in early July of 2019, and distribution samples of major crops in Hengshui were collected. The geographical location of the study area and the distribution of the collected main crop samples are shown in Figure 1. 


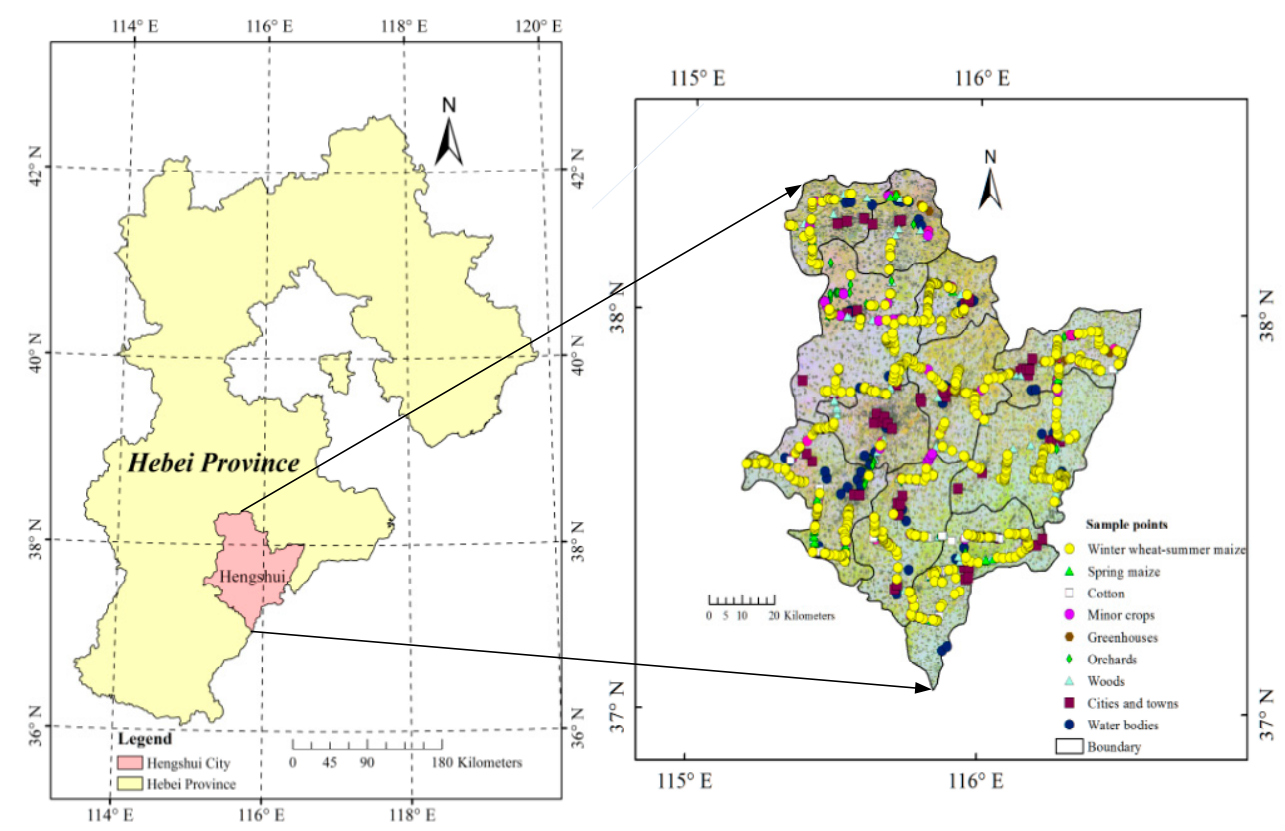

Figure 1. Geographical location and sample distribution of the study area.

\subsection{Data Source}

\subsubsection{Remote Sensing Data}

The GF-6 satellite has panchromatic/multi-spectral (PMS) data and wide field view (WFV) data, in which WFV data adds purple, yellow, and two red edge bands, which have the characteristics of high resolution and wide coverage, and its width can reach $800 \mathrm{~km}$ [24]. In this paper, GF-6 WFV data and its calibration coefficient can be provided and queried from the website of the China Center for Resources Satellite Data and Application (http:/ / www.cresda.com/EN/, (accessed on 8 November 2021)). The main parameter information of GF-6 WFV data in 2019 is shown in Table 1.

Table 1. Main parameter information of GF-6 WFV data in 2019.

\begin{tabular}{|c|c|c|c|c|c|c|}
\hline \multirow{2}{*}{$\begin{array}{c}\text { Band } \\
\text { Number }\end{array}$} & \multirow[t]{2}{*}{ Band Name } & \multirow{2}{*}{$\begin{array}{l}\text { Central Wave- } \\
\text { length/nm }\end{array}$} & \multirow[t]{2}{*}{ FWHM/nm } & \multicolumn{2}{|c|}{$\begin{array}{c}\text { Calibration } \\
\text { Coefficient } /\left(\mathrm{W} \cdot \mathrm{m}^{-2} \cdot \mathrm{sr}^{-1} \cdot \mu \mathrm{m}^{-1}\right)\end{array}$} & \multirow{2}{*}{$\begin{array}{c}\text { Spatial } \\
\text { Resolution/m }\end{array}$} \\
\hline & & & & Gain & Bias & \\
\hline B1 & Blue (B) & 485 & 70 & 0.0705 & 0 & \multirow{8}{*}{16} \\
\hline B2 & Green $(\mathrm{G})$ & 555 & 70 & 0.0567 & 0 & \\
\hline B3 & Red (R) & 660 & 60 & 0.0516 & 0 & \\
\hline B4 & Near infrared (NIR) & 830 & 120 & 0.0322 & 0 & \\
\hline B5 & Red edge 1 (RE1) & 710 & 40 & 0.0532 & 0 & \\
\hline B6 & Red edge 2 (RE2) & 750 & 40 & 0.0453 & 0 & \\
\hline B7 & Purple (P) & 425 & 50 & 0.0786 & 0 & \\
\hline B8 & Yellow (Y) & 610 & 40 & 0.0585 & 0 & \\
\hline
\end{tabular}

This study used GF-6 WFV data of Hengshui City, Hebei Province, China from March to October in 2019, covering the main growth periods of local crops. The image information of the multi-temporal GF-6 WFV data obtained is shown in Table 2.

In this study, the RPC Orthorectification Using Reference Image module in ENVI 5.3 was used for orthorectification, and combined with the off-site absolute calibration coefficient of GF-6 WFV satellite in 2019 for radiometric calibration and FLAASH atmospheric correction, the GF-6 WFV data with DN value of surface reflectance was obtained, so as to calculate and apply NDVI and red edge vegetation indices. 
Table 2. GF-6 WFV data list.

\begin{tabular}{cccc}
\hline Serial Number & GF-6 WFV Image Number & Cloud Coverage & Acquisition Date \\
\hline 1 & GF6_WFV_E113.5_N38.0_20190322_L1A1119859210 & $1 \%$ & 22 March 2019 \\
2 & GF6_WFV_E116.0_N38.0_20190415_L1A1119868166 & $1 \%$ & 15 April 2019 \\
3 & GF6_WFV_E114.0_N38.0_20190506_L1A1119875888 & $24 \%$ & 6 May 2019 \\
4 & GF6_WFV_E119.4_N38.0_20190611_L1A1119890048 & $69 \%$ & 11 June 2019 \\
5 & GF6_WFV_E112.9_N38.0_20190719_L1A1119902447 & $38 \%$ & 18 July 2019 \\
6 & GF6_WFV_E119.0_N38.0_20190828_L1A1119916442 & $1 \%$ & 28 August 2019 \\
7 & GF6_WFV_E116.0_N38.0_20190918_L1A1119926325 & $1 \%$ & 18 Septemper 2019 \\
8 & GF6_WFV_E114.8_N38.0_20191021_L1A1119937425 & $5 \%$ & 21 October 2019 \\
\hline
\end{tabular}

Notes: The annual rainy season in Hengshui City is generally from June to September, with some cloud cover in GF-6 WFV image. Due to the large coverage of GF- 6 WFV images, the cloud coverage of the entire scene image cannot represent the cloud coverage of the study area. The above GF-6 WFV data meet the study requirements.

\subsubsection{Sample Data}

The field sampling of different crops in Hengshui City was conducted in early July 2019. At that time, the winter wheat had been harvested, and the summer maize under the winter wheat-summer maize rotation system had basically sprouted in the stubble farmland, while the spring maize was in the jointing and heading stage, and the cotton was in the budding stage, which was the easiest period to visually judge different crop types in the field. During the field survey, hand-held GPS was used to collect samples of different crop types in 11 counties and districts of Hengshui City, and photos were taken. The survey route was clockwise from north to south and covered most of the farmland in Hengshui City. In this survey, a total of 614 valid samples for different crop types and other ground features were obtained, including 184 winter wheat-summer maize, 100 spring maize, 70 cotton, 60 minor crops, 50 orchards, 30 vegetable greenhouses, 40 woods, 48 towns and cities, and 32 water bodies. In this study, different types of classification samples were digitized as polygons by ArcGIS and divided into training samples and validation samples according to the ratio of 1:1, which were used for crop classification and accuracy evaluation, respectively. The number of different classification samples is shown in Table 3.

Table 3. Number of samples in different class.

\begin{tabular}{ccccc}
\hline Class & $\begin{array}{c}\text { Training } \\
\text { (Pixels) }\end{array}$ & Training (\%) & $\begin{array}{c}\text { Validation } \\
\text { (Pixels) }\end{array}$ & Validation (\%) \\
\hline Winter wheat-summer maize & 5855 & $55.52 \%$ & 4690 & $44.48 \%$ \\
Spring maize & 3434 & $52.92 \%$ & 3055 & $47.08 \%$ \\
Cotton & 1788 & $50.95 \%$ & 1721 & $49.05 \%$ \\
Minor crops & 415 & $51.68 \%$ & 388 & $48.32 \%$ \\
Greenhouses & 396 & $50.32 \%$ & 391 & $49.68 \%$ \\
Orchards & 871 & $50.46 \%$ & 855 & $49.54 \%$ \\
Woods & 1234 & $58.35 \%$ & 881 & $41.65 \%$ \\
Cities and towns & 5164 & $52.84 \%$ & 4609 & $47.16 \%$ \\
Water bodies & 3143 & $47.56 \%$ & 3465 & $52.44 \%$ \\
\hline
\end{tabular}

\subsubsection{Crop Phenology}

The seasonal rhythm and phenological characteristics of different crops can be reflected by the difference of spectrum or vegetation index of multi-temporal remote sensing data [4]. In this study, vegetation indices time series data such as NDVI and red edge vegetation indices were used to identify and classify crops, using the phenological information and spectral differences of different crop types [25].

The crops in the study area include winter wheat, summer maize, spring maize, cotton, fruit trees, peanuts, and soybeans. Among them, winter wheat-summer maize rotation is the main planting type and farming method. Peanuts and soybeans are generally classified as minor crops in actual classification because of their similar phenology and 
minor distribution in the study area [11]. The phenological information of main crops in Hengshui from March to October is shown in Table 4.

Table 4. Phenological information of main crops in Hengshui City.

\begin{tabular}{|c|c|c|c|c|c|c|}
\hline $\begin{array}{c}\text { Phenological } \\
\text { Periods }\end{array}$ & $\begin{array}{l}\text { Winter } \\
\text { Wheat }\end{array}$ & $\begin{array}{l}\text { Summer } \\
\text { Maize }\end{array}$ & $\begin{array}{l}\text { Spring } \\
\text { Maize }\end{array}$ & Cotton & Soybeans & Peanuts \\
\hline 1-15 March & Reviving & & & & & \\
\hline 16-31 March & Developing & & & & & \\
\hline 1-15 April & Developing & & & & & \\
\hline 16-30 April & Developing & & & Sowing & & \\
\hline 1-15 May & Developing & & Sowing & Developing & & \\
\hline 16-31 May & Developing & & Developing & Developing & & Sowing \\
\hline 1-15 June & Maturation & & Developing & Developing & Sowing & Developing \\
\hline 16-30 June & Maturation & Sowing & Developing & Developing & Developing & Developing \\
\hline 1-15 July & & Developing & Developing & Developing & Developing & Developing \\
\hline 16-31 July & & Developing & Developing & Developing & Developing & Developing \\
\hline 1-15 August & & Developing & Developing & Developing & Developing & Developing \\
\hline 16-31 August & & Developing & Maturation & Developing & Developing & Developing \\
\hline 1-15 September & & Developing & Maturation & Maturation & Developing & Developing \\
\hline 16-30 September & & Maturation & & Maturation & Maturation & Maturation \\
\hline 1-15 October & & Maturation & & & Maturation & Maturation \\
\hline 16-31 October & & & & & & \\
\hline
\end{tabular}

\section{Methods}

In this study, the GF-6 WFV data of Hengshui City from March to October 2019 were selected for crop classification based on the characteristics of multiple red edge bands. Firstly, by constructing 10 different red edge vegetation indices time series, combining with principal component analysis (PCA), and using two feature selection and evaluation methods of stepwise discriminant analysis (SDA) and random forest (RF) to evaluate the importance features, the red edge vegetation index time series with the highest feature importance was selected. Combined with NDVI time series and the optimal red edge vegetation index time series, three different time series classification schemes were designed. Finally, an RF classification algorithm was used for land cover and crop classification, and the influence of different vegetation indices time series length on crop classification was analyzed. The technical route of the study is shown in Figure 2. 


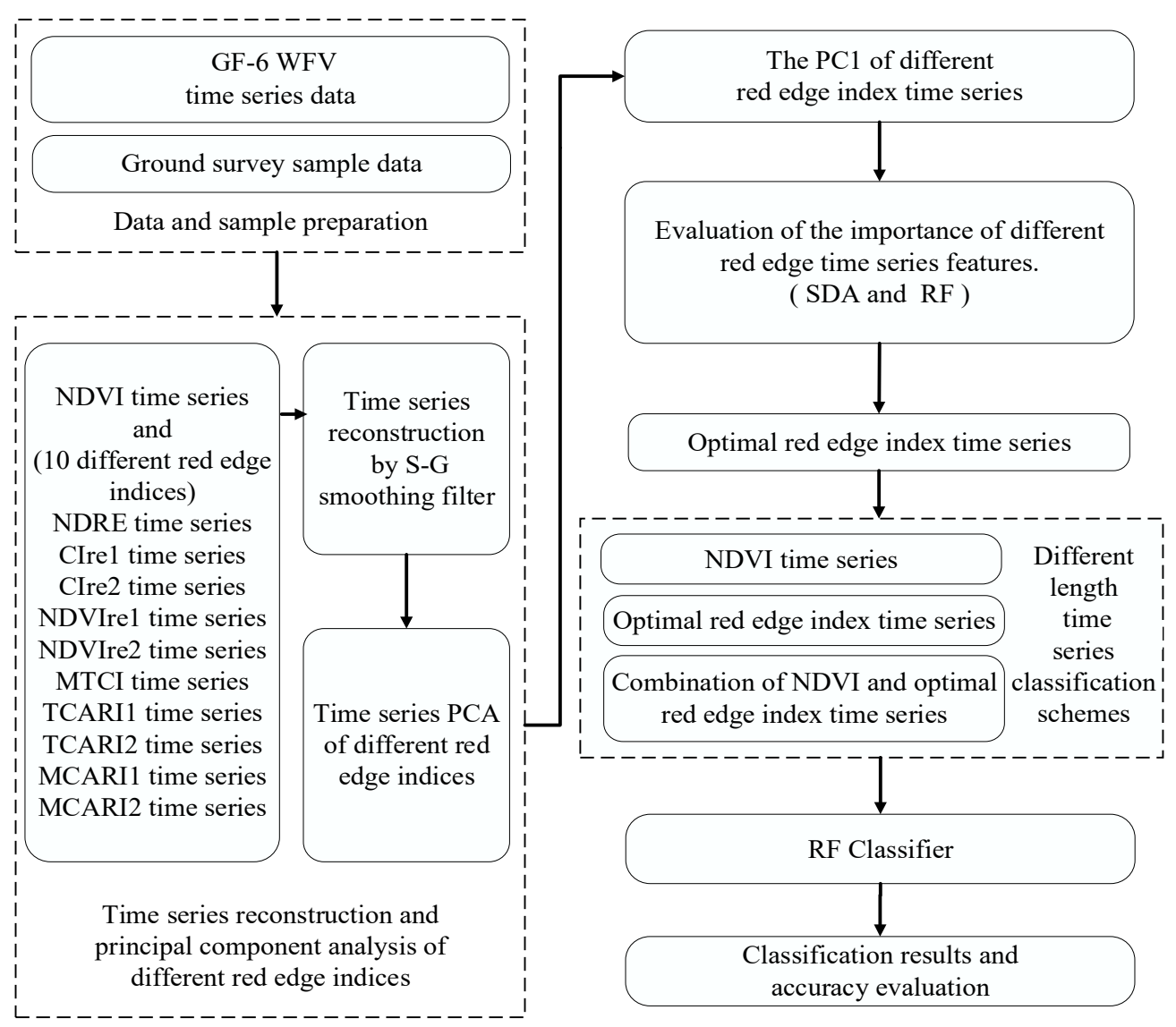

Figure 2. Technical route of the study.

\subsection{Construction of Red Edge Time Series Data Set}

Based on the characteristics of multiple red edge bands in GF-6 WFV data and referring to relevant literatures [26-30], 10 different red edge indices were constructed in this paper, and the calculation formulas are shown in Table 5. In this study, the NDVI and 10 red edge vegetation indices of GF-6 WFV data in different phases were obtained by band operation, and the NDVI time series and 10 red edge indices time series data sets from March to October 2019 were constructed by band synthesis, which can be used for land cover and crop classification [31,32]. The calculation formula of NDVI [33] is shown in Equation (1).

$$
\mathrm{NDVI}=\frac{\rho_{\mathrm{NIR}}-\rho_{\mathrm{R}}}{\rho_{\mathrm{NIR}}+\rho_{\mathrm{R}}}
$$

In the above Equation (1), $\rho$ represents the surface reflectance of a band of GF-6 WFV data, NIR refers to near infrared, and $\mathrm{R}$ refers to red. 
Table 5. Ten different red edge vegetation indices based on GF-6 WFV data.

\begin{tabular}{|c|c|}
\hline Red Edge Indices & Calculation Formula (GF-6 WFV) \\
\hline Chlorophyll Index red edge 1 (CIre1) [34] & $\frac{\rho_{\mathrm{NIR}}}{\rho_{\mathrm{PF} 1}}-1$ \\
\hline Chlorophyll Index red edge 2 (CIre2) [35] & $\frac{\rho_{\mathrm{NER}}}{\rho_{\mathrm{R} F 2}}-1$ \\
\hline Normalized Difference Red Edge (NDRE) [36] & $\frac{\rho_{\mathrm{RE2} 2}-\rho_{\mathrm{RE} 1}}{\rho_{\mathrm{RE}}+\rho_{\mathrm{RE} 1}}$ \\
\hline $\begin{array}{c}\text { Normalized Difference Vegetation Index red } \\
\text { edge } 1 \text { (NDVIre1) [37] }\end{array}$ & $\frac{\rho_{\mathrm{NIR}}-\rho_{\mathrm{RE} 1}}{\rho_{\mathrm{NIR}}+\rho_{\mathrm{RE} 1}}$ \\
\hline $\begin{array}{l}\text { Normalized Difference Vegetation Index red } \\
\text { edge } 2 \text { (NDVIre2) [37] }\end{array}$ & $\frac{\rho_{\mathrm{NIR}}-\rho_{\mathrm{RE} 2}}{\rho_{\mathrm{NIR}}+\rho_{\mathrm{RE} 2}}$ \\
\hline $\begin{array}{l}\text { Modified Chlorophyll Absorption } \\
\text { Ratio Index } 1 \text { (MCARI1) [38] }\end{array}$ & {$\left[\left(\rho_{\mathrm{RE} 1}-\rho_{\mathrm{R}}\right)-0.2 \times\left(\rho_{\mathrm{RE} 1}-\rho_{\mathrm{G}}\right)\right] \times \frac{\rho_{\mathrm{RE} 1}}{\rho_{\mathrm{R}}}$} \\
\hline $\begin{array}{l}\text { Modified Chlorophyll Absorption } \\
\text { Ratio Index } 2 \text { (MCARI2) [38] }\end{array}$ & {$\left[\left(\rho_{\mathrm{RE} 2}-\rho_{\mathrm{R}}\right)-0.2 \times\left(\rho_{\mathrm{RE} 2}-\rho_{\mathrm{G}}\right)\right] \times \frac{\rho_{\mathrm{RE} 2}}{\rho_{\mathrm{R}}}$} \\
\hline $\begin{array}{l}\text { MERIS Terrestrial } \\
\text { Chlorophyll Index (MTCI) [39] }\end{array}$ & $\frac{\rho_{\mathrm{RE} 2}-\rho_{\mathrm{RE} 1}}{\rho_{\mathrm{RE} 1}-\rho_{\mathrm{R}}}$ \\
\hline $\begin{array}{l}\text { Transformed Chlorophyll Absorption } \\
\text { Reflectance Index } 1 \text { (TCARI1) [40] }\end{array}$ & $3 \times\left[\left(\rho_{\mathrm{RE} 1}-\rho_{\mathrm{R}}\right)-0.2 \times\left(\rho_{\mathrm{RE} 1}-\rho_{\mathrm{G}}\right) \times \frac{\rho_{\mathrm{RE} 1}}{\rho_{\mathrm{R}}}\right.$ \\
\hline $\begin{array}{l}\text { Transformed Chlorophyll Absorption } \\
\text { Reflectance Index } 2 \text { (TCARI2) [40] }\end{array}$ & $3 \times\left[\left(\rho_{\mathrm{RE} 2}-\rho_{\mathrm{R}}\right)-0.2 \times\left(\rho_{\mathrm{RE} 2}-\rho_{\mathrm{G}}\right) \times \frac{\rho_{\mathrm{RE} 2}}{\rho_{\mathrm{R}}}\right.$ \\
\hline
\end{tabular}

Notes: $\rho$ means the surface reflectance of a band of GF-6 WFV data, NIR refers to near infrared (830 nm), RE1 refers to red edge $1(710 \mathrm{~nm})$, RE2 refers to red edge $2(750 \mathrm{~nm})$, R refers to red band $(660 \mathrm{~nm}), \mathrm{G}$ refers to green band $(555 \mathrm{~nm})$.

\subsection{Importance Evaluation of Time Series Features of Red Edge Indices}

Feature importance evaluation and feature selection are very important in remote sensing image classification. A good feature selection method can improve classification performance, which is critical for improving classification models and algorithms [41]. Because of the large number and redundancy of 10 different red edge vegetation indices constructed by GF-6 WFV data, this study carried out PCA on the time series data formed by these 10 different red edge vegetation indices [42-44], and calculated the variance contribution rate and cumulative variance contribution rate of the first principal component (PC1) of different red edge indices time series. The PC1 with the highest contribution to variance was selected as the representative of different red edge indices time series to eliminate data redundancy and evaluate the importance of different red edge indices time series.

SDA is a filter feature selection method which evaluates features through the inherent statistical features of data. It is independent of the classification algorithm and has the characteristics of fast speed and good generality, so it is suitable for use as a features prefilter $[45,46]$. The RF feature selection algorithm is an embedded feature selection method which takes feature selection as a part of the learning algorithm and is semi-independent of the learning algorithm. It uses the classification performance of features as the evaluation index, which solves the problems of feature selection and classification or clustering at the same time. It not only improves the speed of feature selection, but also enhances the effect of the classifier $[47,48]$.

The SDA method for feature selection requires that the parameter threshold be set and an appropriate discriminant method is selected. In this study, the entry value of the discriminant function was 2.71 and the removal value of the discriminant function was 3.84 . The Wilks' Lambda method was used for discriminant analysis, and the variance analysis of the variables in the discriminant function was carried out at the same time. In other words, the importance of the feature is measured by the $\mathrm{F}$ value of different variables in the $\mathrm{F}$ test. The larger the $\mathrm{F}$ value is, the higher the importance of corresponding features is, and vice versa $[49,50]$. Specifically, SPSS statistical analysis software [51] was used to realize SDA and evaluation of different time series of red edge indices. The RF algorithm uses the mean decrease Gini (MDG) value of CART decision tree to measure the importance of different features [52,53]; the higher the value of MDG is, the more important the corresponding feature is. Specifically, the RF classifier in the scikit-learn library of Python was called to 
evaluate the importance of features. The study used SDA and RF to evaluate the features of the PC1 of 10 different red edge vegetation indices time series, analyzed the importance of different red edge indices time series features, and selected the best red edge index time series with the highest feature importance score. Three different types of time series data, NDVI time series, optimal red edge time series, NDVI and optimal red edge synthetic time series, were designed to provide reference for the application of red edge features in land cover and crop classification.

\subsection{Time Series Smoothing Filtering}

Because remote sensing time series data are easily affected by the performance of satellite sensors, clouds, atmospheric conditions and other factors, there is usually a lot of noise, which makes the time series curve appear irregular fluctuations, sawtooth and other phenomena, etc. Therefore, it is necessary to smooth and filter the time series data before actual classification to remove the interference of noise, so as to more accurately reflect the phenological changes of different crops, which is beneficial to the remote sensing identification and classification of crops [54].

There are many time series curve smoothing filtering or noise removal methods at present, including maximum value composite (MVC), harmonic analysis of time series (HANTS), the double-logistic function fitting method, SPLINE interpolation method, Savizky-Golay (S-G) filtering method, and so on. S-G filtering is a local fitting processing algorithm based on least square convolution. It can retain the distribution characteristics of the original data such as the relative maximum, minimum, and width in the set filtering window, which is helpful for reflecting the detailed changes of different crops and obtaining better smoothing and fitting results [55-57]. Therefore, the study will adopt the S-G filtering method of IDL language to smooth and denoise three different time series such as NDVI and optimal red edge vegetation index. The specific calculation formula is shown in Equation (2):

$$
Y_{j}^{*}=\frac{\sum_{i=-m}^{i=m} C_{i} \times Y_{j+i}}{N}
$$

In the above equation: $Y_{j+i}$ and $Y_{j}^{*}$ are the time series data before and after reconstruction, respectively. $C_{i}$ is the fitting coefficient of $S-G$ polynomial, which represents the weight of the ith vegetation index value processed by the filter; $m$ is the range of $i$; $N$ is the width of the sliding window, and its value is $2 \mathrm{~m}+1$.

\subsection{Crop Classification with Different Time Series Length}

Currently, the remote sensing identification and classification of most crops need to use multi-temporal remote sensing data of the whole growth period or the whole year of crops, so the crop classification results can only be obtained after the harvest of crops or in the second year, which leads to the low timeliness and practicability of crop identification and classification [58,59]. Recently, many studies have adopted the method of reducing the density of time series or shortening the length of time series for crop classification, which has improved the timeliness of remote sensing classification and the ability of early identification of crops $[9,60]$. This study gradually shortened the length of time series for crop classification and analyzed the impact of different length of time series on the accuracy of crop classification, so as to improve the timeliness of land cover and crop classification.

Based on the GF-6 WFV time series data of eight time steps from March to October 2019 in Hengshui City, Hebei Province, China, three different types of time series such as NDVI and optimal red edge vegetation index were shortened month by month, and the NDVI and red edge vegetation index time series data such as March-September, MarchAugust and March-July were obtained to participate in land cover and crop classification. The classification results of different length time series data were obtained, and then the influence of different vegetation index time series length on the accuracy and timeliness of 
crop classification was analyzed, so as to improve the applicability of shorter time series data in land cover and crop classification.

\subsection{Classification Scheme and Accuracy Evaluation}

The study used an RF algorithm to identify and classify the main crops in the study area. RF is an ensemble learning algorithm based on a CART decision tree proposed by Breiman [61], which is a non-parametric pattern recognition classification method. The RF algorithm can be applied to most data classification without knowing or assuming the distribution of data in advance, which is the key to its superiority to traditional statistical learning methods. It can be regarded as the combination of bagging and random subspace. It is composed of a series of classifiers used to make decisions, expecting to obtain the most "fair" ensemble learning method. To construct each classifier, a part of the samples is randomly selected from the original data set as the sample subspace, and then a new feature subspace is randomly selected from the sample subspace. In this new space, a decision tree is established as the classifier, and the final decision is obtained by voting [62,63]. The RF algorithm has the advantages of high training speed and intelligence, being not easy to over-fit, and having high classification accuracy in crop identification and the classification of remote sensing data. It is widely used in crop classification and area extraction by remote sensing [64].

Confusion matrix is generally used to evaluate the classification accuracy of remote sensing [65]. Confusion matrix, also known as error matrix, is a standard format for precision evaluation, which is expressed in the form of $\mathrm{N}$ rows and $\mathrm{N}$ columns. Specific evaluation indicators include overall accuracy (OA), kappa coefficient, producer accuracy (PA), user accuracy (UA), and F1 accuracy (geometric mean of PA and UA). These classification accuracy indicators can reflect the overall classification accuracy and specific type identification accuracy of remote sensing images from different aspects [66]. F1 accuracy is generally considered as the identification accuracy of crops and the calculation formula is shown in Equation (3):

$$
\mathrm{F} 1=2 \times \mathrm{UA} \times \mathrm{PA} /(\mathrm{UA}+\mathrm{PA}) \times 100 \%
$$

\section{Results}

\subsection{Time Series Evaluation and Optimization Results of Different Red Edge Indices}

In this study, the PCA Rotation module in ENVI 5.3 was used to perform PCA of 10 red edge indices time series. After the calculation operation, the variance contribution rate of the PC1 of different red edge indices time series is shown in Figure 3, and their variance contribution rate is basically more than $80 \%$ (except TCART2 is $68.88 \%$ ). It can be seen that the PC1 of each time series contains most of the information content of the time series data, which can be used as the representative of different red edge indices time series, so as to evaluate the importance of different red edge indices time series. At the same time, the feature importance of the PC1 of 10 different red edge indices time series is evaluated by using SDA and RF feature selection methods, and the PC1 feature importance scores of different red edge indices time series based on SDA and RF are shown in Table 6.

As shown in Table 6, by evaluating the importance of red edge time series features of the PC1 of 10 different red edge vegetation indices time series, the NDRE index has the highest score in the two feature importance evaluation methods, so this study chose the NDRE index for subsequent further study. 


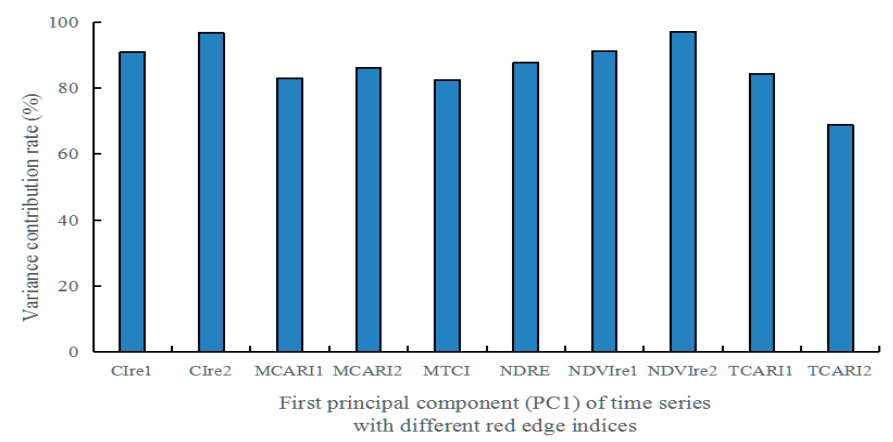

Figure 3. Variance contribution rate of PC1 about 10 different red edge indices time series.

Table 6. Red edge index features importance score based on SDA and RF.

\begin{tabular}{ccc}
\hline The PC1 of Red Edge Time Series & F Value (SDA) & MDG (RF) \\
\hline CIre1-PC1 & 429.842 & 0.121999 \\
CIre2-PC1 & 33.529 & 0.070752 \\
MCARI1-PC1 & 78.717 & 0.086827 \\
MCARI2-PC1 & 87.993 & 0.091048 \\
MTCI-PC1 & 239.771 & 0.110184 \\
NDRE-PC1 & 653.195 & 0.150275 \\
NDVIre1-PC1 & 524.782 & 0.114348 \\
NDVIre2-PC1 & 40.744 & 0.075855 \\
TCARI1-PC1 & 174.389 & 0.096106 \\
TCARI2-PC1 & 134.486 & 0.082606 \\
\hline
\end{tabular}

\subsection{Time Series Smoothing Filtering Results}

The NDVI time series and NDRE red edge index time series constructed by multitemporal GF-6 WFV data were processed by S-G smoothing filtering, and the NDVI and NDRE time series curves of training samples of major crops and the results of S-G smoothing filtering are shown in Figure 4. It shows that the change trends of NDVI and NDRE time series curves of major crops are basically consistent, both of which can reflected the seasonal rhythm and phenological changes of major crops. The time series curve after S-G smoothing can effectively remove the noise and data errors caused by clouds, aerosols, and other factors, so it is more consistent with the seasonal rhythm and phenological changes of different crops.

By comparing the NDVI and NDRE time series curves of different crops before and after S-G smoothing in the study area, it can be concluded that the winter wheat-summer maize rotation with bimodal NDVI and NDRE time series curves and the greenhouse with stable NDVI and NDRE time series curves were the easiest to distinguish from other crops. Among the crops with unimodal NDVI and NDRE time series curves, the NDVI and NDRE time series curves of orchards were easy to distinguish from spring maize, cotton, and minor crops, while the NDVI and NDRE time series curves of spring maize, cotton, and minor crops were similar. Compared with the NDVI time series in August and September, the NDRE time series have a greater difference in relative values, so it is easier to distinguish different single-season crop types by NDRE time series curve. Because the relative difference of NDRE values in August and September is larger than that of NDVI values, the NDRE time series curve is easier to use to distinguish different single-season crop types. 

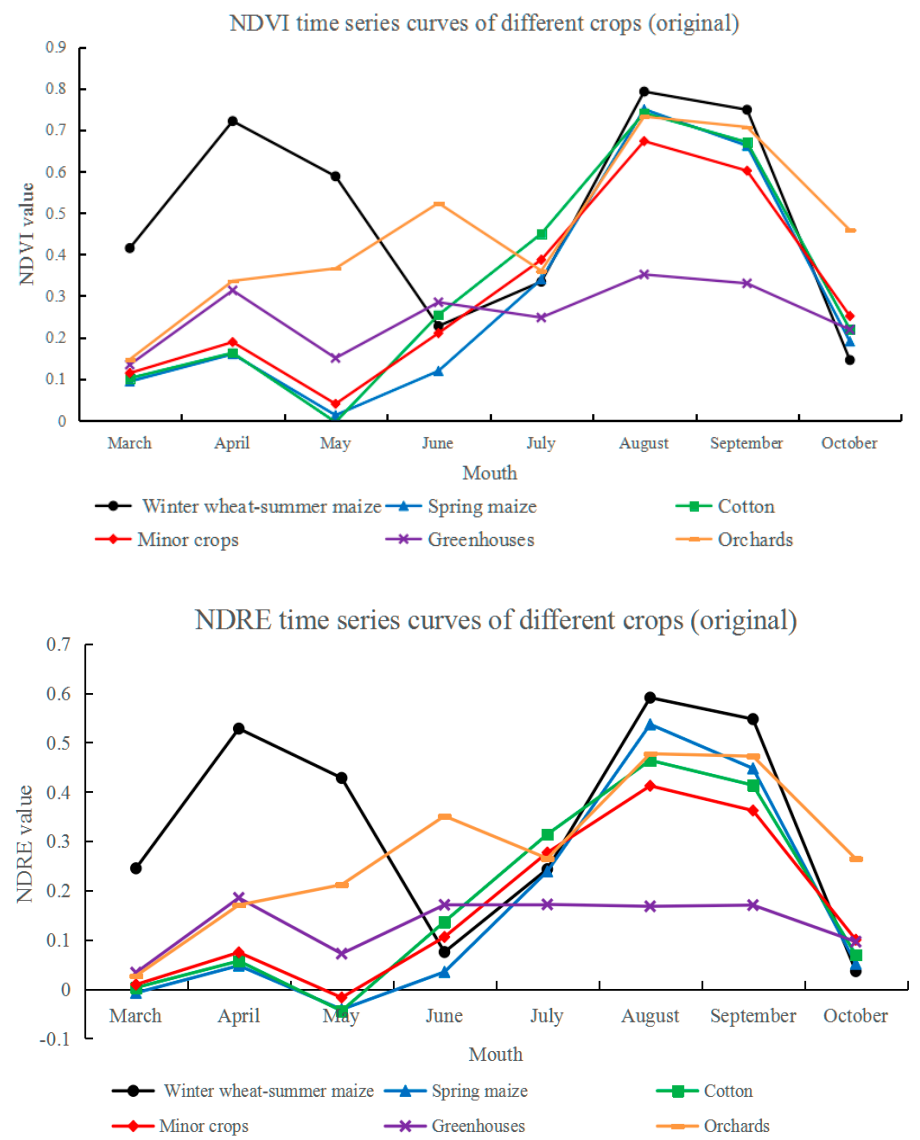

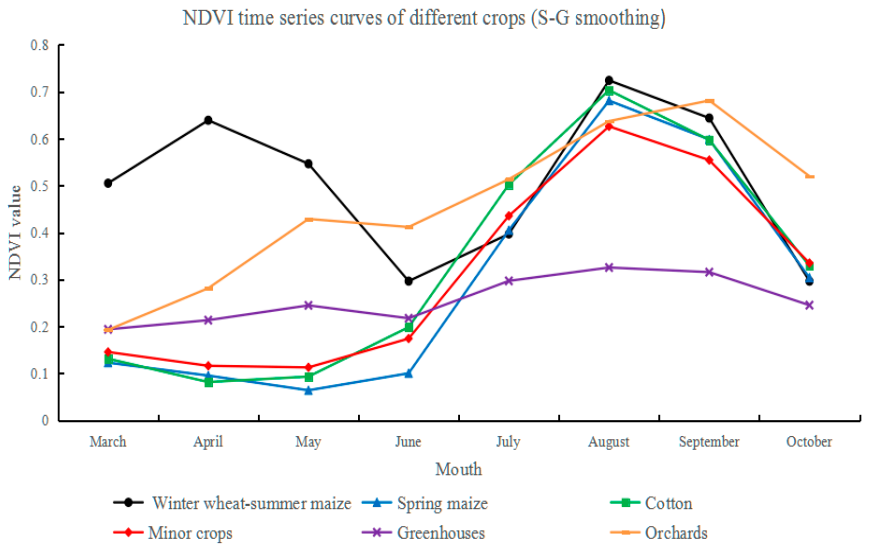

NDRE time series curves of different crops (S-G smoothing)

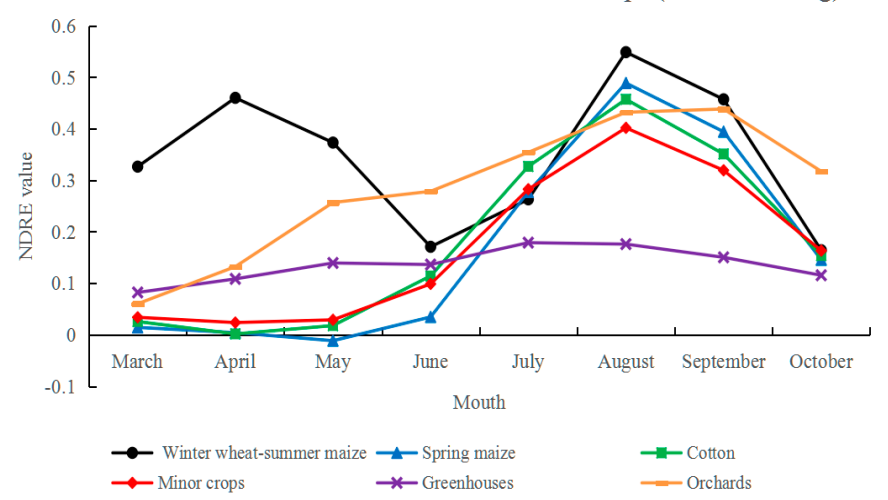

Figure 4. Comparison of NDVI and NDRE time series curves about different crops.

\subsection{The Influence of Red Edge Indices Features on Classification Accuracy}

Combined with the importance evaluation results of the time series features of different red edge indices, the NDRE red edge vegetation index was selected as the representative red edge index to construct three different time series of vegetation indices from March to October in 2019, which were respectively: (1) NDVI time series, (2) NDRE time series, (3) NDVI\&NDRE time series (i.e., the time series of band combination between NDVI series and NDRE series). In this study, the RF classification algorithm was adopted to realize land cover and crop classification by remote sensing, and the different features of NDVI, NDRE, and NDVI\&NDRE time series used for crop classification were compared, so as to analyze the influence of red edge index features on crop classification. The classification accuracy of crops is shown in Table 7.

As shown in Table 7, the OAs of NDVI\&NDRE, NDVI, and NDRE time series classification are $93.86 \%, 92.41 \%$, and $90.93 \%$, and the kappa coefficients are $0.9258,0.9082$, and 0.8901 , respectively. Therefore, the overall classification accuracy of NDVI\&NDRE time series was the highest, followed by NDVI time series, and NDRE time series was the lowest. For the identification accuracy of different crops, the F1 accuracy of different crops in the three vegetation indices time series was similar, but there were still some differences. For spring maize, cotton, and orchards, the NDVI\&NDRE time series had the highest identification accuracy. For winter wheat-summer maize and greenhouse crops, the identification accuracy of NDRE time series was the highest. For minor crops, the identification accuracy of NDVI time series was the highest. Therefore, the red edge vegetation index represented by NDRE can assist NDVI in land cover and crop classification by remote sensing. 
Table 7. Classification accuracy of crops in different vegetation indices time series from March to October in 2019.

\begin{tabular}{|c|c|c|c|c|c|c|c|c|c|}
\hline \multirow[t]{2}{*}{ Class } & \multicolumn{3}{|c|}{$\begin{array}{l}\text { March-October } \\
\text { (NDVI\&NDRE) }\end{array}$} & \multicolumn{3}{|c|}{$\begin{array}{l}\text { March-October } \\
\text { (NDVI) }\end{array}$} & \multicolumn{3}{|c|}{$\begin{array}{l}\text { March-October } \\
\text { (NDRE) }\end{array}$} \\
\hline & PA \% & UA\% & F1\% & PA $\%$ & UA \% & F1\% & PA $\%$ & UA\% & F1\% \\
\hline $\begin{array}{l}\text { Winter wheat-summer } \\
\text { maize }\end{array}$ & 99.53 & 99.79 & 99.66 & 99.45 & 99.85 & 99.65 & 99.87 & 99.83 & 99.85 \\
\hline Spring maize & 95.52 & 89.81 & 92.58 & 94.40 & 89.40 & 91.83 & 95.78 & 88.21 & 91.84 \\
\hline Cotton & 85.76 & 89.84 & 87.75 & 83.90 & 87.57 & 85.70 & 84.66 & 90.22 & 87.35 \\
\hline Minor crops & 36.86 & 42.18 & 39.34 & 37.37 & 42.40 & 39.73 & 32.99 & 46.89 & 38.73 \\
\hline Greenhouses & 89.26 & 86.82 & 88.02 & 79.28 & 78.88 & 79.08 & 91.82 & 87.78 & 89.75 \\
\hline Orchards & 82.92 & 82.83 & 82.87 & 78.60 & 80.38 & 79.48 & 75.20 & 75.12 & 75.16 \\
\hline Woods & 80.36 & 82.33 & 81.33 & 78.21 & 76.81 & 77.50 & 72.76 & 74.28 & 73.51 \\
\hline Cities and towns & 98.26 & 96.71 & 97.48 & 97.33 & 94.20 & 95.74 & 94.97 & 90.45 & 92.65 \\
\hline Water bodies & 95.93 & 99.37 & 97.62 & 93.48 & 98.78 & 96.06 & 87.16 & 94.64 & 90.75 \\
\hline $\mathrm{OA}(\%)$ & & 93.86 & & & 92.41 & & & 90.93 & \\
\hline Kappa coefficient & & 0.9258 & & & 0.9082 & & & 0.8901 & \\
\hline
\end{tabular}

\subsection{Influence of Time Series Length on Classification Accuracy}

Based on the NDVI\&NDRE, NDVI, and NDRE time series from March to October in 2019, seven different length time series such as March to September, March to August and March to July were obtained by gradually shortening the length of the time series. The land cover and crop classification results of NDVI\&NDRE, NDVI, and NDRE with different lengths were obtained by RF classification algorithm. The OAs and kappa coefficients of different length NDVI\&NDRE, NDVI, NDRE time series are shown in Figure 5, and their specific values are shown in Appendix A (Table A1).

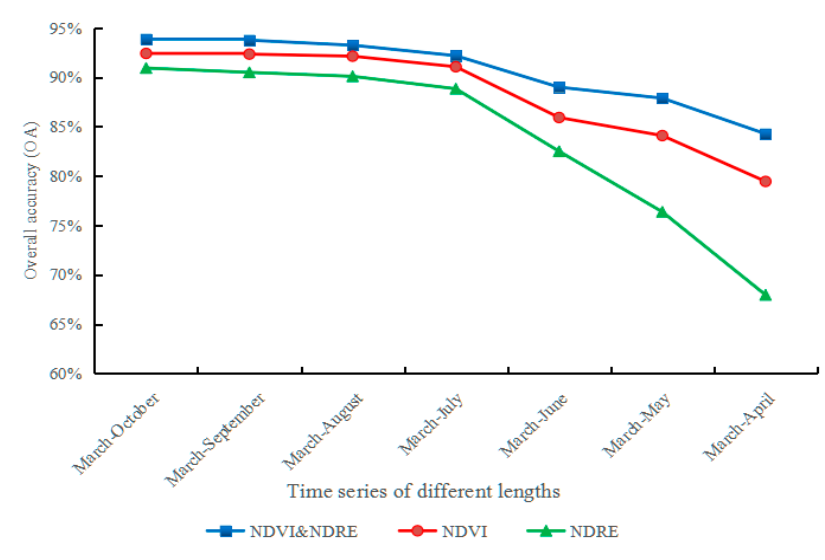

(a)

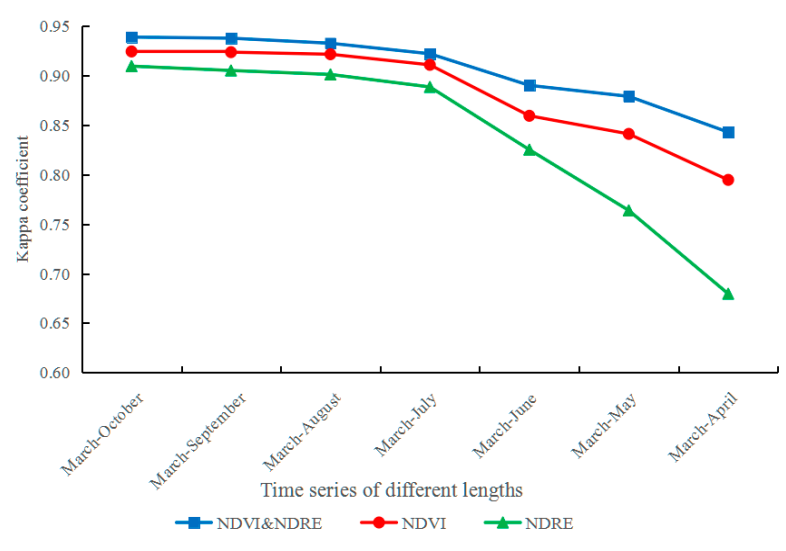

(b)

Figure 5. OAs and kappa coefficients curve of three different types and different length vegetation indices time series. (a) OAs and (b) kappa coefficients.

According to the classification results of three different types of vegetation indices time series with different lengths of NDVI\&NDRE, NDVI, and NDRE, it can be concluded that: (1) With the gradual shortening of the time series length of NDVI\&NDRE, NDVI, and NDRE, the OAs and kappa coefficients of crop classification decrease continuously, and the decline increases gradually; and (2) For the classification results of seven different time series lengths, the classification accuracy of NDVI\&NDRE time series is the highest, followed by the NDVI time series, and the NDRE time series is the lowest. In other words, on the basis of NDVI time series data, supplemented by NDRE red edge vegetation indices, the classification accuracy of crops can be improved from remote sensing data of different length time series. 
In this study, F1 accuracy was used to measure the identification accuracy of different crop types, and its size reflects the identification accuracy of a certain crop. The land cover and crop identification accuracy of three different time series lengths of NDVI\&NDRE, NDVI, and NDRE in 2019 are shown in Figure 6, and their specific values are shown in Appendix A (Tables A2-A4).

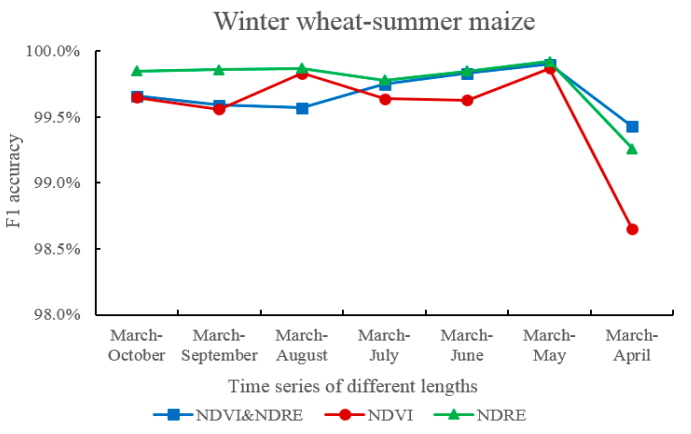

(a)

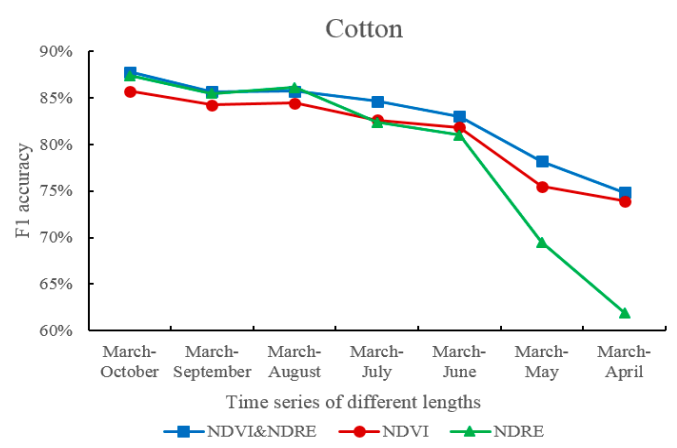

(c)

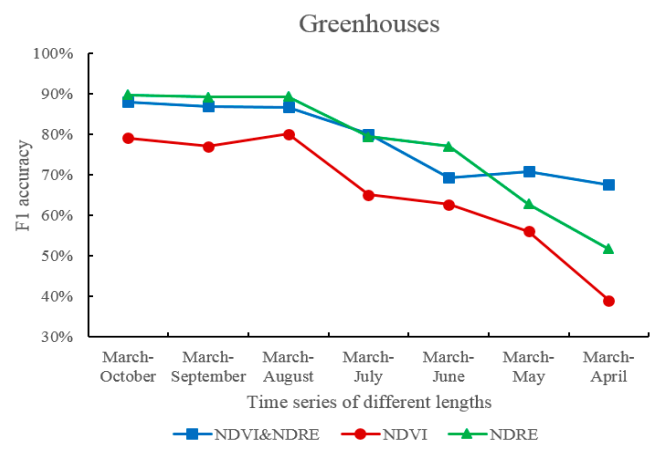

(e)

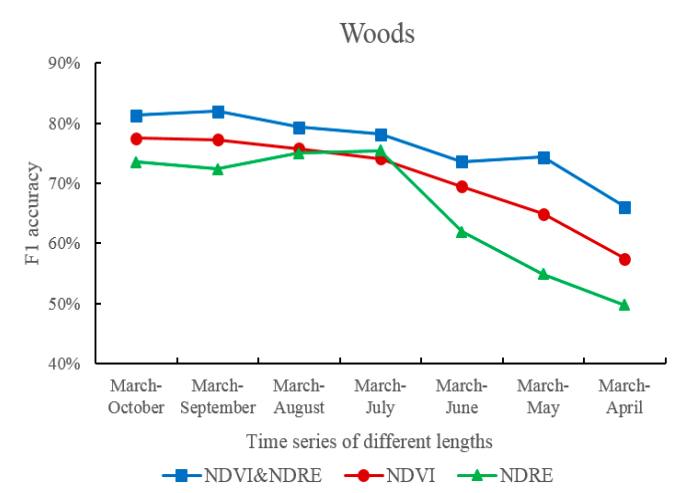

(g)

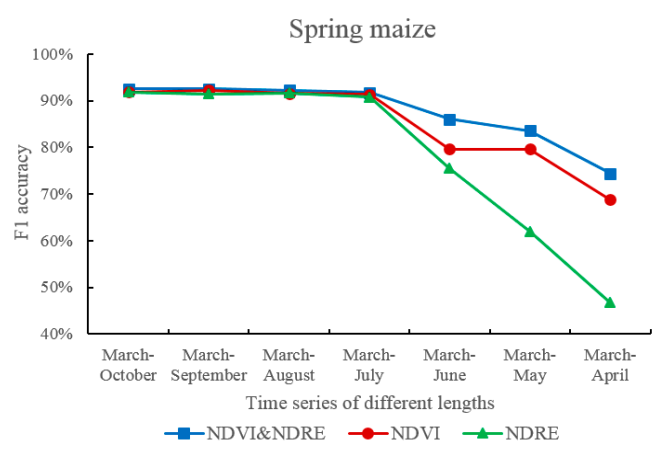

(b)

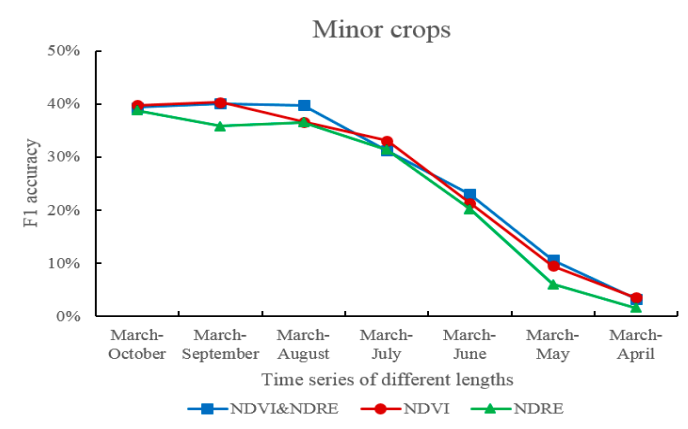

(d)

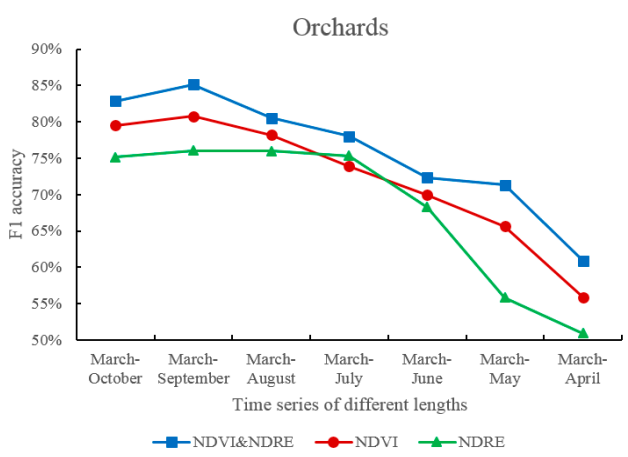

(f)

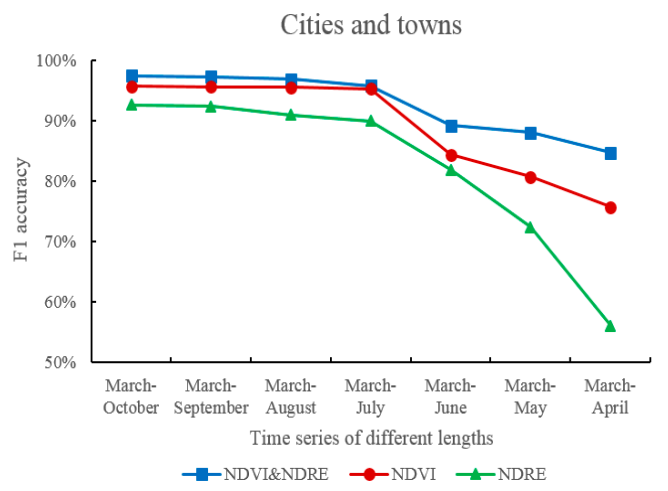

(h)

Figure 6. Cont. 


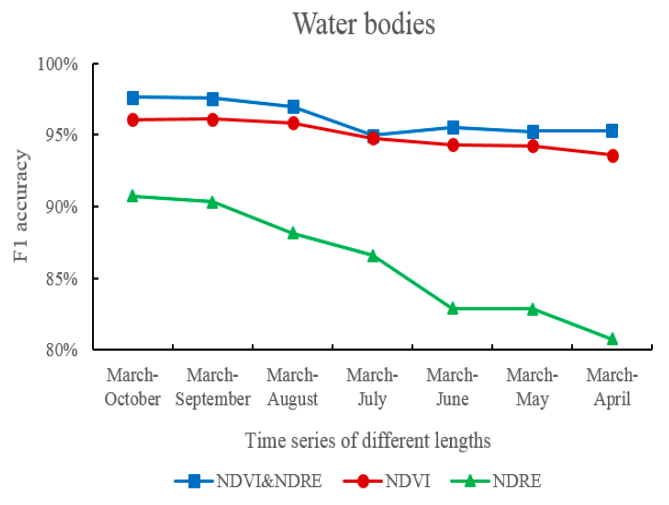

(i)

Figure 6. F1 accuracy of three different time series lengths of NDVI\&NDRE, NDVI, and NDRE about different land cover and crops in 2019. (a) Winter wheat-summer maize, (b) Spring maize, (c) Cotton, (d) Minor crops, (e) Greenhouses, (f) Orchards, (g) Woods, (h) Cities and towns, and (i) Water bodies.

Combined with the identification accuracy (F1 accuracy) of three kinds of time series crops with different lengths of NDVI\&NDRE, NDVI, and NDRE in 2019, the results show that: (1) In addition to winter wheat-summer maize, the identification accuracy of other crops gradually decreased with the shortening of time series length, in which the decrease of NDRE time series was the largest, followed by NDVI time series, and NDVI\&NDRE time series was the smallest; (2) For the crop types of winter wheat-summer maize rotation, there was little difference in the identification of three different time series of NDVI\&NDRE, NDVI, and NDRE, in which the identification accuracy of NDRE was slightly higher than that of NDVI\&NDRE and NDVI, while NDVI was relatively the lowest; and (3) For spring maize, cotton, and greenhouses, combined with the identification accuracy of NDVI\&NDRE, NDVI, and NDRE from March to October, March to September and March to August, the identification accuracy of NDRE red edge index time series was basically higher than that of NDVI time series, and the identification accuracy of NDVI\&NDRE time series was the highest. For the identification accuracy of NDVI\&NDRE, NDVI, and NDRE time series from March to July, March to June, March to May and March to April, it was found that the identification accuracy of NDVI time series was basically higher than NDRE time series, while the identification accuracy of NDVI\&NDRE time series was the highest.

\subsection{Crop Planting Structure and Distribution in the Study Area}

According to the crop classification accuracy of three vegetation indices time series with different lengths and types, the classification scheme of NDVI\&NDRE time series from March to October in the study area was selected, and the classification results of different land cover and crops in Hengshui City in 2019 are shown in Figure 7.

As shown in Figure 7, the results of land cover and crop classification reflected the planting situation and spatial distribution of different crops in Hengshui City in 2019. Winter wheat-summer maize rotation was the most important planting type, which was distributed in most areas of Hengshui City. Spring maize was mainly distributed in Anping County, Wuqiang County and Wuyi County in the northeast of Hengshui City. Planting spring maize can save water resources, which conforms to the local climate and national seasonal fallow policy. Cotton was mainly distributed in Jizhou City, Zaoqiang County and Gucheng County in the south of Hengshui City, which is close to the cotton producing area in southern Hebei Province, and is a traditional cotton planting area. Greenhouses were mainly concentrated in the eastern part of Raoyang County in Hengshui City. Orchards were mainly concentrated in the north of Shenzhou County in Hengshui City. The minor crops in Hengshui were mainly peanuts and soybeans, including pepper and potatoes, etc., which were distributed more dispersed in the whole district of Hengshui City, and there was no large-scale centralized planting and distribution. 


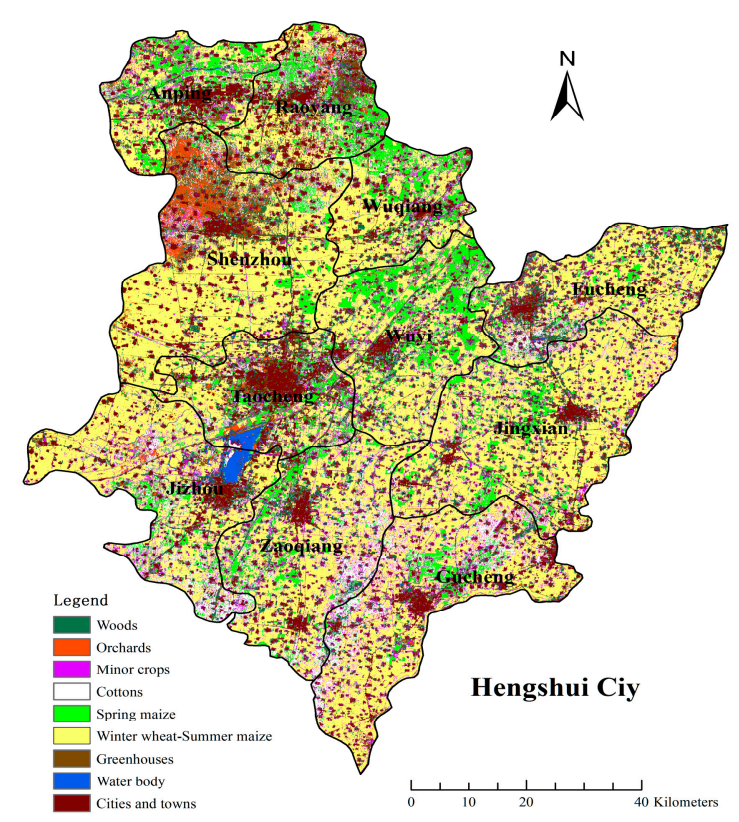

Figure 7. Classification results of different land cover and crops in Hengshui City in 2019.

\section{Discussion}

According to the characteristics of two red edge bands of GF-6 WFV data, a variety of different red edge indices time series were constructed by using GF-6 WFV time series data from March to October 2019. Through data smooth reconstruction and classification feature importance evaluation, the red edge index time series represented by NDRE was selected. Combined with NDVI time series, three different vegetation indices time series classification schemes of NDVI, NDRE, and NDVI\&NDRE were designed. The RF classification algorithm was used to analyze the effects of different time series length and optimal red edge index features on crop classification accuracy, and the application characteristics of red edge features in crop classification of multi-temporal or time series data were discussed. For the specific research results, firstly, the feature importance of the PC1 of 10 different red edge indices time series (Table 5) was evaluated by using SDA and RF. The results showed that the PC1 of NDRE time series had the highest F value (653.195) and MDG value (0.150275) in the two evaluation methods of feature importance, respectively, so NDRE was selected as the representative red edge index for the study of time series crop classification. Then, based on multi-temporal GF-6 WFV data, this paper constructed three different vegetation indices time series of Hengshui City from March to October 2019, which are as follows: (1) NDVI time series, (2) NDRE time series, (3) NDVI\&NDRE time series. Finally, the remote sensing identification and classification of different crops in Hengshui City were realized by using RF classification algorithm, and the OAs and kappa coefficients of three different time series classifications of NDVI, NDRE, and NDVI\&NDRE were obtained Appendix A (Table A1), in which the OA and kappa coefficient of NDVI\&NDRE time series were the highest. In addition to the crop classification by remote sensing of three different vegetation indices time series of NDVI, NDRE, and NDVI\&NDRE in Hengshui City from March to October 2019, the crop classification accuracy of seven different length time series of March-September, March-August, March-July, March-June, March-May, and March-April were also analyzed by gradually shortening the length of three different vegetation indices time series, and also adopted the method of RF classification. At the same time, the remote sensing identification accuracy of different types and lengths of vegetation indices time series for specific types of crops was analyzed by introducing F1 accuracy. The red edge index represented by NDRE is helpful to improve the identification accuracy of different types of crops. The specific values can be found in Appendix A (Tables A2-A4).

At present, there are many studies on the application of red edge indices to crop remote sensing classification based on multi-temporal or time series data. For example, 
Gerstmann et al. [18] analyzed the phenological differences and separability of crops such as corn, rape and winter wheat by using the red edge index features of multi-temporal RapidEye data. Wu et al. [19] constructed the red edge normalized vegetation index (RENDVI) time series based on the multi-temporal Sentinel-2A data, and combined with the NDVI time series to carry out the fine classification of crops. Xiao et al. [20] established red edge spectral index (RESI) time series through multi-temporal Sentinel-2 data to realize remote sensing identification and mapping of rubber plantations in Louang Namtha Province, northern Laos. Huang et al. [29] discussed the impact of different classification feature combinations of time series Sentinel-2A data on classification accuracy by introducing parcel point set and modified chlorophyll absorption red edge index (MCARI). Although the above-mentioned studies have confirmed that the red edge index feature of multi-temporal RapidEye and Sentinel-2 can improve the accuracy of remote sensing identification and classification of crops, only one red edge index feature is used in the study, and there is no further selection and evaluation of different red edge indices features. In terms of early identification and classification of crops with different length of time series data, Hao P et al. [62] used multi-temporal Sentinel-1 and Sentinel-2 data to form an irregular time series with $10 \mathrm{~m}$ resolution, and the improved artificial immune network (IAIN) classification method was used to analyze the effects of different classification features and time series length on crop classification. Maponya et al. [60] selected a series of Sentinel-2 remote sensing images to design four classification schemes with different feature combinations. By shortening the length of time series and using a variety of machine learning classification methods, it is concluded that SVM and RF methods can obtain higher classification accuracy 8 weeks before the harvest of main crops, which can be used for early identification of crop types in the growing season.

In a word, this study makes full use of the red edge features of multi-temporal GF-6 WFV data, designs different red edge indices time series, and selects the red edge index time series represented by NDRE. Combined with NDVI time series, this paper studies the crop classification with different time series lengths and discusses the identification and classification of crops with different time series lengths combined with red edge features. For the identification and classification of specific crop types, it is concluded that the red edge index time series represented by NDRE can improve the identification accuracy of different crop types to varying degrees, and compared with NDVI time series, it is more conducive to identify summer crops with similar phenological features from August to October, such as summer maize, spring maize, and cotton, which is helpful to the fine identification and classification of crops. However, the combination of NDVI and NDRE time series is generally considered to have the highest accuracy in crop classification of time series data.

\section{Conclusions}

This study aims at constructing a variety of red edge indices time series and NDVI time series based on GF-6 WFV data of eight time steps from March to October 2019. The red edge index time series represented by NDRE is selected by PCA, SDA, and RF, and three different time series classification schemes of NDVI, NDRE, and NDVI\&NDRE are designed. Then the RF classification algorithm is used to analyze the effects of different time series length and red edge indices on land cover and crop classification. The main conclusions of this study are as follows:

(1) Two feature selection methods, SDA and RF, are used to evaluate the classification feature importance of the PC1 of 10 red edge indices time series, including NDRE, NDVIre1, NDVIre2, CIre1, CIre2, MCARI1, MCARI2, TCARI1, TCARI2, and MTCI. It is found that the PC1 of NDRE time series corresponding to SDA and RF respectively has the highest F value and MDG value, so the red edge index time series represented by NDRE time series is selected;

(2) For the three different vegetation indices time series of NDVI\&NDRE, NDVI, and NDRE, regardless of the length of the time series, the OA and kappa coefficient of 
NDVI\&NDRE time series are the highest, followed by NDVI time series, and the NDRE time series has the lowest OA and kappa coefficient. Therefore, it can be obtained that NDVI time series is more conducive to improve the overall classification accuracy of crops than NDRE time series, and NDRE time series can assist NDVI time series to improve the accuracy of crop identification and classification;

(3) With the gradual shortening of the time series length of NDVI\&NDRE, NDVI, and NDRE, the OA and kappa coefficient of crop classification in the study area gradually decreased, and the decline is gradually accelerated, that is, the shortening of time series length is significantly not conducive to improving the accuracy of crop classification;

(4) For specific crop types, especially three different length time series from MarchOctober, March-September and March-August, it is found that the identification accuracy (F1 accuracy) of winter wheat-summer maize, spring maize, cotton and greenhouse of NDRE time series is basically higher than that of NDVI time series. This shows that NDRE time series is more conducive to identify summer maize, spring maize and cotton with similar phenology from August to October, while NDVI\&NDRE time series has the highest identification accuracy for crops such as spring maize, cotton and greenhouse. For the identification accuracy of main crops in three different time series of NDVI\&NDRE, NDVI and NDRE from March-July, March-June, March-May and March-April, it is found that the identification accuracy of NDVI time series is basically higher than that of NDRE time series, while the identification accuracy of NDVI\&NDRE time series is the highest.

In conclusion, the red edge index represented by NDRE constructed by GF-6 WFV data can assist NDVI to study land cover and crop classification of different length time series remote sensing data, and help to improve the accuracy and timeliness of crop identification and classification. For the three different types of vegetation indices time series of NDVI\&NDRE, NDVI and NDRE, because the NDVI\&NDRE time series combines the features of NDVI and red edge index, the classification accuracy is basically the highest for both the overall classification accuracy and the identification accuracy of main crops in the study area, which shows that the red edge features and phenological features reflected in the NDRE time series plays an important role in fine identification and classification of crops. In the study, we fully tap the application potential of the new red edge bands of GF-6 WFV data in land cover and crop classification of time series data, which provides a reference for the research of red edge indices in crop identification and classification of different length time series. In addition, it is helpful to improve the accuracy and timeliness of crop classification, and promote the popularization and application of GF-6, Sentinel-2 and other optical satellite data with red edge bands in the field of agricultural remote sensing.

Author Contributions: Conceptualization, X.H., Q.M., Y.Z. and Y.K.; methodology, Y.K., X.H., Q.M., Y.Z. and L.Z.; investigation and data acquisition Y.K., M.L. and M.Z.; data analysis and validation, Y.K., Q.M., L.Z. and M.L.; supervision, X.H. and Q.M.; writing—original draft preparation, Y.K.; writing-review and editing, Y.K., X.H., Q.M., Y.Z., L.Z., M.L. and M.Z. All authors contributed to the discussion, provided suggestions to improve the manuscript and checked the writing. All authors have read and agreed to the published version of the manuscript.

Funding: This study was funded by the Major Projects of High Resolution Earth Observation Systems of National Science and Technology (05-Y30B01-9001-19/20-1), the Major Project of High Resolution Earth Observation System of China (30-Y20A07-9003-17/18) and the National Key Research and Development Program of China (2020YFC0833100).

Data Availability Statement: Not applicable.

Acknowledgments: Thanks very much for the GF-6 WFV data provided by China Center for Resources Satellite Data and Application (http:/ / www.cresda.com/EN/, (accessed on 8 November 2021)).

Conflicts of Interest: The authors declare no conflict of interest. 


\section{Appendix A}

Table A1 provides the OAs and kappa coefficients of NDVI\&NDRE, NDVI, and NDRE time series about different length in 2019. Tables A2-A4 provide crop identification accuracy (F1 accuracy) of NDVI\&NDRE, NDVI, and NDRE time series about different lengths in 2019.

Table A1. OAs and kappa coefficients of NDVI\&NDRE, NDVI, and NDRE time series about different length in 2019.

\begin{tabular}{ccccccccc}
\hline \multicolumn{2}{c}{ Time Series Length } & $\begin{array}{c}\text { March- } \\
\text { October }\end{array}$ & $\begin{array}{c}\text { March- } \\
\text { September }\end{array}$ & $\begin{array}{c}\text { March- } \\
\text { August }\end{array}$ & $\begin{array}{c}\text { March- } \\
\text { July }\end{array}$ & $\begin{array}{c}\text { March- } \\
\text { June }\end{array}$ & $\begin{array}{c}\text { March- } \\
\text { May }\end{array}$ & $\begin{array}{c}\text { March- } \\
\text { April }\end{array}$ \\
\hline \multirow{2}{*}{$\begin{array}{c}\text { NDVI\& } \\
\text { NDRE }\end{array}$} & $\begin{array}{c}\text { OA (\%) } \\
\text { Kappa } \\
\text { coefficient }\end{array}$ & 93.86 & 93.75 & 93.24 & 92.18 & 88.99 & 87.88 & 84.27 \\
\multirow{2}{*}{ NDVI } & $\begin{array}{c}\text { OA (\%) } \\
\text { Kappa } \\
\text { coefficient }\end{array}$ & 92.41 & 92.34 & 92.13 & 91.06 & 85.92 & 84.09 & 79.45 \\
\hline \multirow{2}{*}{ NDRE } & $\begin{array}{c}\text { OA (\%) } \\
\text { Kappa } \\
\text { coefficient }\end{array}$ & 0.9082 & 0.9073 & 0.9047 & 0.8919 & 0.8295 & 0.8071 & 0.7516 \\
\hline
\end{tabular}

Table A2. Crop identification accuracy of different length NDVI\&NDRE time series in 2019.

\begin{tabular}{|c|c|c|c|c|c|c|c|c|}
\hline Class & Time Series Length & $\begin{array}{l}\text { March- } \\
\text { October }\end{array}$ & $\begin{array}{c}\text { March- } \\
\text { September }\end{array}$ & $\begin{array}{l}\text { March- } \\
\text { August }\end{array}$ & $\begin{array}{l}\text { March- } \\
\text { July }\end{array}$ & $\begin{array}{l}\text { March- } \\
\text { June }\end{array}$ & $\begin{array}{l}\text { March- } \\
\text { May }\end{array}$ & $\begin{array}{l}\text { March- } \\
\text { April }\end{array}$ \\
\hline & $\begin{array}{l}\text { Winter wheat-summer } \\
\text { maize }\end{array}$ & $99.66 \%$ & $99.59 \%$ & $99.57 \%$ & $99.75 \%$ & $99.83 \%$ & $99.90 \%$ & $99.43 \%$ \\
\hline & Spring maize & $92.58 \%$ & $92.54 \%$ & $92.26 \%$ & $91.78 \%$ & $86.04 \%$ & $83.53 \%$ & $74.45 \%$ \\
\hline & Cotton & $87.75 \%$ & $85.64 \%$ & $85.69 \%$ & $84.60 \%$ & $83.00 \%$ & $78.19 \%$ & $74.85 \%$ \\
\hline & Minor crops & $39.34 \%$ & $40.06 \%$ & $39.76 \%$ & $31.21 \%$ & $22.96 \%$ & $10.59 \%$ & $3.26 \%$ \\
\hline & Greenhouses & $88.02 \%$ & $86.91 \%$ & $86.72 \%$ & $80.10 \%$ & $69.30 \%$ & $70.84 \%$ & $67.58 \%$ \\
\hline & Orchards & $82.87 \%$ & $85.11 \%$ & $80.51 \%$ & $78.02 \%$ & $72.30 \%$ & $71.29 \%$ & $60.92 \%$ \\
\hline & Woods & $81.33 \%$ & $81.99 \%$ & $79.33 \%$ & $78.15 \%$ & $73.65 \%$ & $74.32 \%$ & $66.04 \%$ \\
\hline & Cities and towns & $97.48 \%$ & $97.35 \%$ & $96.94 \%$ & $95.89 \%$ & $89.30 \%$ & $88.07 \%$ & $84.75 \%$ \\
\hline & Water bodies & $97.62 \%$ & $97.55 \%$ & $96.99 \%$ & $94.99 \%$ & $95.56 \%$ & $95.26 \%$ & $95.30 \%$ \\
\hline
\end{tabular}

Table A3. Crop identification accuracy of different length NDVI time series in 2019.

\begin{tabular}{|c|c|c|c|c|c|c|c|c|}
\hline Class & Time Series Length & $\begin{array}{l}\text { March- } \\
\text { October }\end{array}$ & $\begin{array}{c}\text { March- } \\
\text { September }\end{array}$ & $\begin{array}{l}\text { March- } \\
\text { August }\end{array}$ & $\begin{array}{c}\text { March- } \\
\text { July }\end{array}$ & $\begin{array}{l}\text { March- } \\
\text { June }\end{array}$ & $\begin{array}{l}\text { March- } \\
\text { May }\end{array}$ & $\begin{array}{l}\text { March- } \\
\text { April }\end{array}$ \\
\hline & $\begin{array}{c}\text { Winter wheat summer } \\
\text { maize }\end{array}$ & $99.65 \%$ & $99.56 \%$ & $99.83 \%$ & $99.64 \%$ & $99.63 \%$ & $99.87 \%$ & $98.65 \%$ \\
\hline & Spring maize & $91.83 \%$ & $92.20 \%$ & $91.53 \%$ & $91.38 \%$ & $79.58 \%$ & $79.58 \%$ & $68.79 \%$ \\
\hline & Cotton & $85.70 \%$ & $84.23 \%$ & $84.43 \%$ & $82.61 \%$ & $81.82 \%$ & $75.46 \%$ & $73.93 \%$ \\
\hline & Minor crops & $39.73 \%$ & $40.28 \%$ & $36.63 \%$ & $33.08 \%$ & $21.26 \%$ & $9.419 \%$ & $3.510 \%$ \\
\hline & Greenhouses & $79.08 \%$ & $77.04 \%$ & $80.05 \%$ & $65.06 \%$ & $62.73 \%$ & $56.04 \%$ & $39.02 \%$ \\
\hline & Orchards & $79.48 \%$ & $80.78 \%$ & $78.18 \%$ & $73.87 \%$ & $69.93 \%$ & $65.62 \%$ & $55.87 \%$ \\
\hline & Woods & $77.50 \%$ & $77.29 \%$ & $75.78 \%$ & $74.10 \%$ & $69.49 \%$ & $64.88 \%$ & $57.43 \%$ \\
\hline & Cities and towns & $95.74 \%$ & $95.64 \%$ & $95.59 \%$ & $95.33 \%$ & $84.43 \%$ & $80.79 \%$ & $75.73 \%$ \\
\hline & Water bodies & $96.06 \%$ & $96.11 \%$ & $95.85 \%$ & $94.79 \%$ & $94.34 \%$ & $94.25 \%$ & $93.59 \%$ \\
\hline
\end{tabular}


Table A4. Crop identification accuracy of different length NDRE time series in 2019.

\begin{tabular}{|c|c|c|c|c|c|c|c|c|}
\hline Class & Time Series Length & $\begin{array}{l}\text { March- } \\
\text { October }\end{array}$ & $\begin{array}{c}\text { March- } \\
\text { September }\end{array}$ & $\begin{array}{l}\text { March- } \\
\text { August }\end{array}$ & $\begin{array}{l}\text { March- } \\
\text { July }\end{array}$ & $\begin{array}{l}\text { March- } \\
\text { June }\end{array}$ & $\begin{array}{l}\text { March- } \\
\text { May }\end{array}$ & $\begin{array}{l}\text { March- } \\
\text { April }\end{array}$ \\
\hline & $\begin{array}{c}\text { Winter wheat summer } \\
\text { maize }\end{array}$ & $99.85 \%$ & $99.86 \%$ & $99.87 \%$ & $99.78 \%$ & $99.85 \%$ & $99.92 \%$ & $99.26 \%$ \\
\hline & Spring maize & $91.84 \%$ & $91.47 \%$ & $91.69 \%$ & $90.80 \%$ & $75.52 \%$ & $62.01 \%$ & $46.70 \%$ \\
\hline & Cotton & $87.35 \%$ & $85.43 \%$ & $86.09 \%$ & $82.36 \%$ & $80.99 \%$ & $69.49 \%$ & $61.91 \%$ \\
\hline & Minor crops & $38.73 \%$ & $35.75 \%$ & $36.48 \%$ & $31.39 \%$ & $20.18 \%$ & $5.966 \%$ & $1.517 \%$ \\
\hline & Greenhouses & $89.75 \%$ & $89.22 \%$ & $89.35 \%$ & $79.38 \%$ & $77.06 \%$ & $62.82 \%$ & $51.75 \%$ \\
\hline & Orchards & $75.16 \%$ & $76.06 \%$ & $75.99 \%$ & $75.31 \%$ & $68.29 \%$ & $55.81 \%$ & $50.93 \%$ \\
\hline & Woods & $73.51 \%$ & $72.34 \%$ & $75.01 \%$ & $75.46 \%$ & $61.92 \%$ & $54.92 \%$ & $49.75 \%$ \\
\hline & Cities and towns & $92.65 \%$ & $92.43 \%$ & $91.06 \%$ & $90.03 \%$ & $81.92 \%$ & $72.42 \%$ & $56.11 \%$ \\
\hline & Water bodies & $90.75 \%$ & $90.32 \%$ & $88.17 \%$ & $86.58 \%$ & $82.88 \%$ & $82.87 \%$ & $80.78 \%$ \\
\hline
\end{tabular}

\section{References}

1. Khaliq, A.; Peroni, L.; Chiaberge, M. Land cover and crop classification using multitemporal sentinel-2 images based on crops phenological cycle. In Proceedings of the 2018 IEEE Workshop on Environmental, Energy, and Structural Monitoring Systems (EESMS), Salerno, Italy, 21-22 June 2018; pp. 1-5.

2. Zhao, C.J. Advances of research and application in remote sensing for agriculture. Trans. Chin. Soc. Agric. Mach. 2014, 45, 277-293.

3. Conese, C.; Maselli, F. Use of multi-temporal information to improve classification performance of TM scenes in complex terrain. ISPRS J. Photogramm. Remote Sens. 1991, 46, 187-197. [CrossRef]

4. Gómez, C.; White, J.C.; Wulder, M.A. Optical remotely sensed time series data for land cover classification: A review. ISPRS J. Photogramm. Remote Sens. 2016, 116, 55-72. [CrossRef]

5. Murthy, C.S.; Raju, P.V.; Badrinath, K.V.S. Classification of wheat crop with multi-temporal images: Performance of maximum likelihood and artificial neural networks. Int. J. Remote Sens. 2003, 24, 4871-4890. [CrossRef]

6. Zhong, L.; Hu, L.; Zhou, H. Deep learning based multi-temporal crop classification. Remote Sens. Environ. 2019, 221, 430-443. [CrossRef]

7. Wardlow, B.D.; Egbert, S.L.; Kastens, J.H. Analysis of time-series MODIS 250 m vegetation index data for crop classification in the US Central Great Plains. Remote Sens. Environ. 2007, 108, 290-310. [CrossRef]

8. Hao, P.; Wang, L.; Niu, Z.; Aablikim, A.; Huang, N.; Xu, S.; Chen, F. The potential of time series merged from Landsat-5 TM and HJ-1 CCD for crop classification: A case study for Bole and Manas Counties in Xinjiang, China. Remote Sens. 2014, 6, 7610-7631. [CrossRef]

9. Zhan, Y.; Muhammad, S.; Hao, P.; Niu, Z. The effect of EVI time series density on crop classification accuracy. Optik 2018, 157, 1065-1072. [CrossRef]

10. Belgiu, M.; Csillik, O. Sentinel-2 cropland mapping using pixel-based and object-based time-weighted dynamic time warping analysis. Remote Sens. Environ. 2018, 204, 509-523. [CrossRef]

11. Liu, J.; Wang, L.M.; Yang, F.G.; Yang, L.B.; Wang, X.L. Remote sensing estimation of crop planting area based on HJ time-series images. Trans. Chin. Soc. Agric. Eng. 2015, 31, 199-206.

12. Zhang, R.Q.; Wang, S.A.; Gao, W.L.; Sun, W.L.; Wang, J.L.; Niu, L.A. Remote-sensing classification method of county-level agricultural crops using time-series NDVI. Trans. Chin. Soc. Agric. Mach. 2015, 46, 246-252.

13. Huang, J.; Hou, Y.; Su, W.; Liu, J.; Zhu, D. Mapping corn and soybean cropped area with GF-1 WFV data. Trans. Chin. Soc. Agric. Mach. 2017, 33, 164-170.

14. Lebrini, Y.; Boudhar, A.; Laamrani, A.; Htitiou, A.; Lionboui, H.; Salhi, A.; Chehbouni, A.; Benabdelouahab, T. Mapping and Characterization of Phenological Changes over Various Farming Systems in an Arid and Semi-Arid Region Using Multitemporal Moderate Spatial Resolution Data. Remote Sens. 2021, 13, 578. [CrossRef]

15. Li, X.C.; Xu, X.G.; Wang, J.H.; Wu, H.F.; Jing, X.L.; Li, C.J.; Bao, Y.S. Crop classification recognition based on time-series images from HJ satellite. Trans. Chin. Soc. Agric. Eng. 2013, 29, 169-176.

16. Xu, Q.; Yang, G.; Long, H.; Wang, C.; Li, X.; Huang, D. Crop information identification based on MODIS NDVI time-series data. Trans. Chin. Soc. Agric. Eng. 2014, 30, 134-144.

17. Wang, W.J.; Zhang, X.; Zhao, Y.D.; Wang, S.D. Cotton Extraction Method of Integrated Multi-features based on Multi-temporal Landsat 8 Images. J. Remote Sens. 2017, 21, 115-124.

18. Gerstmann, H.; Möller, M.; Gläßer, C. Optimization of spectral indices and long-term separability analysis for classification of cereal crops using multi-spectral RapidEye imagery. Int. J. Appl. Earth Obs. Geoinf. 2016, 52, 115-125. [CrossRef]

19. Wu, J.; Lu, Y.N.; Li, C.B.; Li, Q.H. Fine Classification of County Crops Based on Multi-temporal Images of Sentinel-2A. Trans. Chin. Soc. Agric. Mach. 2019, 50, 194-200.

20. Xiao, C.; Li, P.; Feng, Z.; Liu, Y.; Zhang, X. Sentinel-2 red-edge spectral indices (RESI) suitability for mapping rubber boom in Luang Namtha Province, northern Lao PDR. Int. J. Appl. Earth Obs. Geoinf. 2020, 93, 102176. [CrossRef]

21. $\mathrm{Li}, \mathrm{H}$. A study on the uncertainty of regional winter wheat growth simulation from a crop model using remote sensing data assimilation. Ph.D Thesis, Chinese Academy of Agricultural Sciences, Beijing, China, 2016. 
22. Huang, G.Q.; Zhao, Q.G. Mode of rotation/fallow management in typical areas of China and its development strategy. Acta Pedol. Sin. 2018, 55, 283-292.

23. Xie, H.; Cheng, L.; Lv, T. Factors influencing farmer willingness to fallow winter wheat and ecological compensation standards in a groundwater funnel area in Hengshui, Hebei Province, China. Sustainability 2017, 9, 839. [CrossRef]

24. Wang, M.; Guo, B.B.; Long, X.X.; Xue, L.; Cheng, Y.F.; Jin, S.Y.; Zhou, X. On-orbit geometric calibration and accuracy verification of GF-6 WFV camera. Acta Geod. Cartogr. Sin. 2020, 49, 171-180.

25. Foerster, S.; Kaden, K.; Foerster, M.; Itzerott, S. Crop type mapping using spectral-temporal profiles and phenological information. Comput. Electron. Agric. 2012, 89, 30-40. [CrossRef]

26. Fang, C.Y.; Wang, L.; Xu, H.Q. A comparative study of different red edge indices for remote sensing detection of urban grassland health status. J. Geo-Inf. Sci. 2017, 19, 1382-1392.

27. Xie, Q.Y. Research on leaf area index retrieve methods based on the red edge bands from multi-platform remote sensing data. Ph.D Thesis, University of Chinese Academy of Sciences (Institute of Remote Sensing and Digital Earth, Chinese Academy of Sciences), Beijing, China, 2017.

28. Hang, S.Y.; Yang, L.; Chen, X.; Yao, Y. Study of typical arid crops classification based on machine learning. Spectrosc. Spectr. Anal. 2018, 38, 3169-3176.

29. Gu, F.; Ding, J.L.; Ge, X.Y.; Gao, S.B.; Wang, J.Z. Estimation of Chlorophyll Content in Typical Oasis Vegetation in Arid Area Based on Sentinel-2 Data. Arid. Zone Res. 2019, 36, 924-934.

30. Zhang, L.; Gong, Z.N.; Wang, Q.W.; Jin, D.; Wang, X. Wetland mapping of Yellow River Delta wetlands based on multi-feature optimization of Sentinel-2 images. J. Remote Sens. 2019, 23, 313-326.

31. Zhao, Y.S. Principles and Methods of Remote Sensing Application Analysis, 2nd ed.; Science Press: Beijing, China, 2013 ; pp. $174-175$.

32. Deng, S.B. ENVI Remote Sensing Image Processing Method, 2nd ed.; Higher Education Press: Beijing, China, 2014; pp. 381-384.

33. Rouse, J.W.; Haas, R.H.; Schell, J.A.; Deering, D.W. Monitoring vegetation systems in the Great Plains with ERTS. NASA Spec. Publ. 1974, 351, 309-317.

34. Gitelson, A.A.; Gritz, Y.; Merzlyak, M.N. Relationships between leaf chlorophyll content and spectral reflectance and algorithms for non-destructive chlorophyll assessment in higher plant leaves. J. Plant Physiol. 2003, 160, 271-282. [CrossRef]

35. Gitelson, A.A.; Keydan, G.P.; Merzlyak, M.N. Three-band model for noninvasive estimation of chlorophyll, carotenoids, and anthocyanin contents in higher plant leaves. Geophys. Res. Lett. 2006, 33, L11402. [CrossRef]

36. Gitelson, A.A.; Merzlyak, M.N. Spectral reflectance changes associated with autumn senescence of Aesculus hippocastanum L. and Acer platanoides L. leaves. Spectral features and relation to chlorophyll estimation. J. Plant Physiol. 1994, 143, 286-292. [CrossRef]

37. Barnes, E.M.; Clarke, T.R.; Richards, S.E.; Colaizzi, P.D.; Haberland, J.; Kostrzewski, M.; Moran, M.S. Coincident detection of crop water stress, nitrogen status and canopy density using ground based multispectral data. In Proceedings of the Fifth International Conference on Precision Agriculture, Bloomington, MN, USA, 16-19 July 2000; Volume 1619.

38. Daughtry, C.S.; Walthall, C.L.; Kim, M.S.; De Colstoun, E.B.; McMurtrey, J.E. Estimating corn leaf chlorophyll concentration from leaf and canopy reflectance. Remote Sens. Environ. 2000, 74, 229-239. [CrossRef]

39. Dash, J.; Curran, P.J. MTCI: The MERIS terrestrial chlorophyll index. MERIS User Workshop 2003, 549, 23.

40. Haboudane, D.; Miller, J.R.; Pattey, E.; Zarco-Tejada, P.J.; Strachan, I.B. Hyperspectral vegetation indices and novel algorithms for predicting green LAI of crop canopies: Modeling and validation in the context of precision agriculture. Remote Sens. Environ. 2004, 90, 337-352. [CrossRef]

41. Blum, A.; Langley, P. Selection of relevant features and examples in machine learning. Artif. Intell. 1997, 97, 245-271. [CrossRef]

42. Jolliffe, I.T. Principal Component Analysis, 2nd ed.; Springer: Berlin, Germany, 2002; pp. $299-302$.

43. Palsson, F.; Sveinsson, J.R.; Ulfarsson, M.O.; Benediktsson, J.A. Model-based fusion of multi-and hyperspectral images using PCA and wavelets. IEEE Trans. Geosci. Remote Sens. 2014, 53, 2652-2663. [CrossRef]

44. Xia, M.; Jia, K.; Zhao, W.; Liu, S.; Wei, X.; Wang, B. Spatio-temporal changes of ecological vulnerability across the Qinghai-Tibetan Plateau. Ecol. Indic. 2021, 123, 107274. [CrossRef]

45. Costanza, M.C.; Afifi, A.A. Comparison of Stopping Rules in Forward Stepwise Discriminant Analysis. J. Am. Stat. Assoc. 1979, 74, 777-785. [CrossRef]

46. Xiao, Y.; Jiang, Q.; Wang, B.; Li, Y.; Liu, S.; Cui, C. Object based land-use classification based on hybrid feature selection method of combining Relief F and PSO. Trans. Chin. Soc. Agric. Eng. 2016, 32, 211-216.

47. Belgiu, M.; Drăguț, L. Random forest in remote sensing: A review of applications and future directions. ISPRS J. Photogramm. Remote Sens. 2016, 114, 24-31. [CrossRef]

48. Zhang, H.; Li, Q.; Liu, J.; Du, X.; Dong, T.; McNairn, H.; Shang, J. Object-based crop classification using multi-temporal SPOT-5 imagery and textural features with a Random Forest classifier. Geocarto Int. 2018, 33, 1017-1035. [CrossRef]

49. Pu, R.; Landry, S. A comparative analysis of high spatial resolution IKONOS and WorldView-2 imagery for mapping urban tree species. Remote Sens. Environ. 2012, 124, 516-533. [CrossRef]

50. Zhang, H.; Li, Q.; Liu, J.; Shang, J.; Du, X.; McNairn, H.; Liu, M. Image Classification Using RapidEye Data: Integration of Spectral and Textual Features in a Random Forest Classifier. IEEE J. Sel. Top. Appl. Earth Obs. Remote Sens. 2017, 10, 5334-5349. [CrossRef]

51. Homer, M.S. An introduction to secondary data analysis with IBM SPSS statistics. Educ. Rev. 2018, 70, 251-252. [CrossRef] 
52. Pedregosa, F.; Varoquaux, G.; Gramfort, A.; Michel, V.; Thirion, B.; Grisel, O.; Duchesnay, E. Scikit-learn: Machine learning in Python. J. Mach. Learn. Res. 2011, 12, 2825-2830.

53. Sebastian, R. Python Machine Learning; Packt Publishing: Birmingham, UK, 2015; pp. 124-126.

54. Liu, J.; Zhan, P. The impacts of smoothing methods for time-series remote sensing data on crop phenology extraction. In Proceedings of the 2016 IEEE International Geoscience and Remote Sensing Symposium, Beijing, China, 10-15 July 2016; pp. 2296-2299.

55. Savitzky, A.; Golay, M.J. Smoothing and differentiation of data by simplified least squares procedures. Anal. Chem. 1964, 36, 1627-1639. [CrossRef]

56. Chen, J.; Jönsson, P.; Tamura, M.; Gu, Z.; Matsushita, B.; Eklundh, L. A simple method for reconstructing a high-quality NDVI time-series data set based on the Savitzky-Golay filter. Remote Sens. Environ. 2004, 91, 332-344. [CrossRef]

57. White, M.A.; Nemani, R.R. Real-time monitoring and short-term forecasting of land surface phenology. Remote Sens. Environ. 2006, 104, 43-49. [CrossRef]

58. Gallego, J.; Craig, M.; Michaelsen, J.; Bossyns, B.; Fritz, S. Best Practices for Crop Area Estimation with Remote Sensing; Joint Research Center: Ispra, Italy, 2008.

59. Maponya, M.G.; Van Niekerk, A.; Mashimbye, Z.E. Pre-harvest classification of crop types using a Sentinel-2 time-series and machine learning. Comput. Electron. Agric. 2020, 169, 105164. [CrossRef]

60. Hao, P.; Tang, H.; Chen, Z.; Liu, Z. Early-season crop mapping using improved artificial immune network (IAIN) and Sentinel data. PeerJ 2018, 6, e5431. [CrossRef]

61. Breiman, L. Random forests. Mach. Learn. 2001, 45, 5-32. [CrossRef]

62. Li, H. Statistical Learning Methods; Tsinghua University Press: Beijing, China, 2012; pp. 67-73.

63. Zhou, Z.H. Machine Learning; Tsinghua University Press: Beijing, China, 2016; pp. 178-181.

64. Ma, Y.; Jiang, Q.G.; Meng, Z.G.; Li, Y.H.; Wang, D.; Liu, H.X. Classification of land use in farming area based on random forest algorithm. Trans. Chin. Soc. Agric. Mach. 2016, 47, 297-303.

65. Cohen, J. A Coefficient of Agreement for Nominal Scales. Educ. Psychol. Meas. 1960, 20, 37-46. [CrossRef]

66. Congalton, R.G. A review of assessing the accuracy of classifications of remotely sensed data. Remote Sens. Environ. 1991, 37, 35-46. [CrossRef] 